\title{
Design, Synthesis, and Biological Evaluation of Novel 6H-Benzo[c]chromen-6-one Derivatives as Potential Phosphodiesterase II Inhibitors
}

\author{
Long Tang ${ }^{1,2,3}$, Jianchun Jiang ${ }^{1,2, *}$, Guoqiang Song ${ }^{3}$, Yajing Wang ${ }^{3}$, Ziheng Zhuang ${ }^{3}$, Ying Tan ${ }^{3}$, Yan Xia ${ }^{3}$, \\ Xianfeng Huang ${ }^{3}$ and Xiaoqing Feng ${ }^{3, *}$ \\ 1 Institute of Chemical Industry of Forest Products, Chinese Academy of Forestry, Nanjing 210042, China; \\ 00009205@cczu.edu.cn \\ 2 School of Chemical Engineering, Nanjing Forestry University, Nanjing 210037, China \\ 3 School of Pharmaceutical Engineering \& Life Science, Changzhou University, Changzhou 213164, China; \\ sgq@cczu.edu.cn (G.S.); cathywang@cczu.edu.cn (Y.W.); zzh2010@cczu.edu.cn (Z.Z.); \\ 15435108@smail.cczu.edu.cn (Y.T.); xy19105500550xy@163.com (Y.X.); huangxf@cczu.edu.cn (X.H.) \\ * Correspondence: jiangjc@icifp.cn (J.J.); fxqfw@cczu.edu.cn (X.F.)
}

check for

updates

Citation: Tang, L.; Jiang, J.; Song, G.; Wang, Y.; Zhuang, Z.; Tan, Y.; Xia, Y.; Huang, $X . ;$ Feng, $X$. Design, Synthesis, and Biological Evaluation of Novel 6H-Benzo[c]chromen-6-one

Derivatives as Potential Phosphodiesterase II Inhibitors. Int. J Mol. Sci. 2021, 22, 5680. https:// doi.org/10.3390/ijms22115680

Academic Editor: Oxana

V. Galzitskaya

Received: 15 April 2021

Accepted: 25 May 2021

Published: 26 May 2021

Publisher's Note: MDPI stays neutral with regard to jurisdictional claims in published maps and institutional affiliations.

Copyright: (c) 2021 by the authors. Licensee MDPI, Basel, Switzerland. This article is an open access article distributed under the terms and conditions of the Creative Commons Attribution (CC BY) license (https:// creativecommons.org/licenses/by/ $4.0 /)$

\begin{abstract}
Urolithins (hydroxylated $6 \mathrm{H}$-benzo[c]chromen-6-ones) are the main bioavailable metabolites of ellagic acid (EA), which was shown to be a cognitive enhancer in the treatment of neurodegenerative diseases. As part of this research, a series of alkoxylated $6 H$-benzo[c]chromen-6-one derivatives were designed and synthesized. Furthermore, their biological activities were evaluated as potential PDE2 inhibitors, and the alkoxylated $6 \mathrm{H}$-benzo[c]chromen-6-one derivative $1 \mathrm{f}$ was found to have the optimal inhibitory potential $\left(\mathrm{IC}_{50}: 3.67 \pm 0.47 \mu \mathrm{M}\right)$. It also exhibited comparable activity in comparison to that of BAY 60-7550 in vitro cell level studies.
\end{abstract}

Keywords: alkoxylated 6H-benzo[c]chromen-6-one; phosphodiesterase II; inhibitors; biological activities

\section{Introduction}

Ellagic acid (EA) is an important part of the pharmacological activity of mellow compounds, which are widely distributed in the bark, root, leaf, and fruit of plants. It has a wide range of pharmacological activities, such as antioxidation, antitumor, antimutation, antibacterial, anti-inflammatory, antiviral, and myocardial protection [1]. In recent years, EA showed great therapeutic potential in the treatment of neurodegenerative diseases such as typical Alzheimer's disease (AD) and Parkinson's disease (PD) because of its neuroprotective effects and ability to delay neurodegeneration of aging in the mouse model of AD [2-8]. However, the applications of EA were limited in the field of health care products and cosmetics due to poor oral bioavailability. There are no EA derivatives available on the market in the pharmaceutical field.

Urolithins are main intestinal metabolites, which are derived from the metabolism of EA through tannolactone ring and dihydroxylation [9-12]. Urolithins have more advantages in absorption than EA, which may be the final material basis for the biological activities of EA [13]. Urolithins are widely distributed in the urine, feces, and bile of mammals such as humans, rats, mice, cattle, and pigs [13-15]. The reports on the biological activity of urolithins mainly focus on the antioxidation, anti-inflammatory, and antitumor properties, as well as its regulation of intestinal flora and inhibition of end products of protein glycosylation $[9,10,13,16,17]$. Some studies reported that both Urolithin A and Urolithin B are involved in neuroprotection because they can significantly inhibit the formation of protein glycosylation end products [18]. Urolithin A can activate neuroprotective mechanisms, such as activating SIRT-1 in differentiated ReNcell VM human nerve cells. SIRT-1 is a deacetylase that regulates DNA expression, cell apoptosis, and aging, and participates in the physiological or pathological processes of organisms by deacetylating 
substrate proteins. The activation of SIRT- 1 is related to the neuroprotective effect of Urolithin A in nerve cells [19]. Urolithin B can cross the blood-brain barrier and has few side effects on the body, so it may provide therapeutic benefits for neurodegenerative diseases associated with oxidative stress and microglial activation [20]. Therefore, urolithins show great therapeutic potential in the treatment of neurodegenerative diseases.

Phosphodiesterase inhibition received much attention for the potential treatment of central nervous system (CNS) disorders. The role of PDEs in the augmentation of cyclic nucleotide signaling makes these enzymes as attractive targets for the enhancing neuronal communication. PDE2A is the only subtype of PDE2 in mammalian species, which is mainly expressed in brain and heart, but remains low in peripheral tissues [21-24]. Compared with normal people, the level of PDE2A in the brain of AD patients is increased. Laurent Gomez et al. summarized the development of PDE2 inhibitors for the treatment of cognitive disorders [25,26]. In 2013, Zhu et al. reported the composite crystal structure of PDE2 and the highly selective inhibitor BAY 60-7550 (protein number: 4HTX, http:/ / www.rcsb.org, accessed on 20 March 2021), which provided the basis for the rational design of small molecule ligands targeted to PDE2 [27]. However, there are no PDE2 drugs in the markets so far. Therefore, further studies are urgently needed to develop PDE2 inhibitors to meet clinical needs.

In the present study, urolithins were selected as leading compounds, and a series of novel urolithin( $6 H$-benzo[c]chromen-6-one)-derivatives were designed and synthesized to screen PDE2 inhibitors. The potential neuroprotective effects of resultant compounds were evaluated through PDE2 inhibition effects firstly. The compounds with higher PDE2 inhibition activity were further evaluated by corticosterone-induced cytotoxicity in the hippocampal HT-22 cells.

\section{Results and Discussion}

\subsection{Synthetic Pathways}

Our initial exploration focused on introducing different substituents into the hydroxy scaffold at the 3-position of urolithin while keeping the lactone ring fixed. Thus, various kinds of novel $6 \mathrm{H}$-benzo[c]chromen-6-one derivatives were designed and synthesized. The general routes for synthesizing $6 \mathrm{H}$-benzo[c]chromen-6-one derivatives 1 and 2 are shown in Scheme 1 [28]. First, the reaction of 2-bromobenzoic acids and resorcinol in the presence of $\mathrm{CuSO}_{4}$ and $\mathrm{NaOH}$ provides the intermediate I and II. Next, intermediate I and II were reacted with various kinds of halides including iodomethane, alkyl bromides, and heterocyclic bromides to generate the desired $6 \mathrm{H}$-benzo[c]chromen-6-one derivatives 1 and 2 in moderate to good yields.<smiles>[R]c1ccc(C(=O)O)c(Br)c1</smiles><smiles>Oc1cccc(O)c1</smiles>

(a)<smiles>[R]c1ccc2c(c1)c(=O)oc1cc(O)ccc12</smiles>

$$
\begin{aligned}
\text { I, } R & =\mathrm{H} \\
\text { II, } \mathrm{R} & =\mathrm{OMe}
\end{aligned}
$$

$R^{1} X$

(b)<smiles>[Z1]Oc1ccc2c(c1)c(=O)oc1cc([R])ccc12</smiles>

$1, \mathrm{R}=\mathrm{H}$

2, $\mathrm{R}=\mathrm{OMe}$

Scheme 1. Synthesis of $6 \mathrm{H}$-benzo[c]chromen-6-one derivatives 1 and 2. Reagents and conditions: (a) $5 \% \mathrm{CuSO}, \mathrm{NaOH}$, $\mathrm{H}_{2} \mathrm{O}$, reflux, $1.2 \mathrm{~h}$; (b) $\mathrm{K}_{2} \mathrm{CO}_{3}, \mathrm{DMF}, 80 \sim 120^{\circ} \mathrm{C}, 3.5 \sim 30 \mathrm{~h}$.

\subsection{Enzymatic Assays}

Our previous work reported [29] that a propylphenyl group in the classic PDE2 inhibitor BAY 60-7550 was well-accommodated through a hydrophobic-induced binding pocket located under L770 of the protein. Therefore, for urolithin-derivatives in this work, only by bearing certain length and lipophilicity can the $\mathrm{R}^{1}$ group interact properly within 
the pocket. Based on this rule, the $6 \mathrm{H}$-benzo[c]chromen-6-one derivatives 1 and 2 were evaluated based on their effects on PDE2 inhibitory activities. As shown in Figures 1 and 2, most of the derivatives gave the appropriate values of $C \log P(2.0-5.0)$, indicating the good blood-brain barrier penetration. Moreover, compounds $1 \mathbf{a}-\mathbf{u}$ and $2 \mathbf{a}-\mathbf{w}$ were also tested in vitro for PDE2 inhibitory activities, showing that $\mathrm{R}^{1}$ group remarkably affected the PDE2 inhibitory activities (as illustrated in Table 1). For compounds $1 \mathbf{a}-\mathbf{u}$, when $\mathrm{R}^{1}$ group alkane substituted groups with less than five carbons, the PDE2 inhibitory activity is relatively good. To our delight, compound 1f significantly affected the PDE2 inhibitory activities $\left(\mathrm{IC}_{50}=3.67 \pm 0.47 \mu \mathrm{M}\right)$. For compounds $2 \mathbf{a}-\mathbf{w}$, although compound $2 \mathbf{i}$ had the best PDE2 inhibitory activity, it also needed to be reformed.

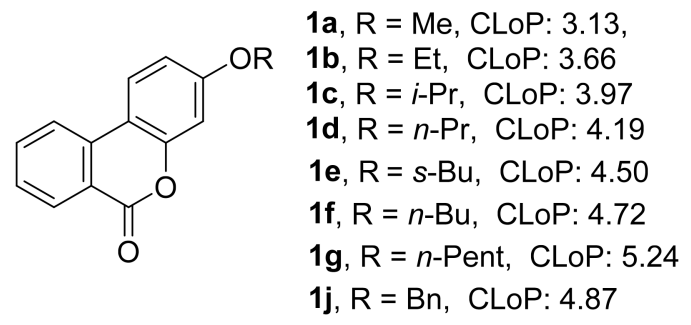<smiles>CCC(=O)COc1ccc2c(c1)oc(=O)c1ccccc12</smiles><smiles>O=c1oc2cc(OCC3CCOCC3)ccc2c2ccccc12</smiles><smiles>O=c1oc2cc(OCCn3cccn3)ccc2c2ccccc12</smiles>

1k, CLoP: 3.32

1i, CLoP: 3.38<smiles>O=c1oc2cc(OCCO)ccc2c2ccccc12</smiles>

1m, CLoP: 2.26<smiles>O=c1oc2cc(OCC3CCCO3)ccc2c2ccccc12</smiles>

1n, CLoP: 3.49<smiles>O=c1oc2cc(Oc3ncccn3)ccc2c2ccccc12</smiles>

1I, CLoP: 3.38<smiles>O=c1oc2cc(OC3OCCO3)ccc2c2ccccc12</smiles>

10, CLoP: 2.87<smiles>COc1cc(COc2ccc3c(c2)oc(=O)c2ccccc23)cc(OC)c1</smiles>

1p, CLoP: 4.91<smiles>Cc1cc(COc2ccc3c(c2)oc(=O)c2ccccc23)n(C)n1</smiles><smiles>O=c1oc2cc(OCc3cccnc3)ccc2c2ccccc12</smiles>

1q, CLoP: 3.28

1r, CLoP:3.40<smiles>O=c1oc2cc(OCC3CCCC3)ccc2c2ccccc12</smiles>

1s, CLoP: 5.22<smiles>O=c1oc2cc(OCc3ccc(COc4ccc5c(c4)oc(=O)c4ccccc45)cc3)ccc2c2ccccc12</smiles>

1t. CLoP: 3.86

Figure 1. CLoP values of $6 H$-benzo[c]chromen-6-one derivatives 1. 


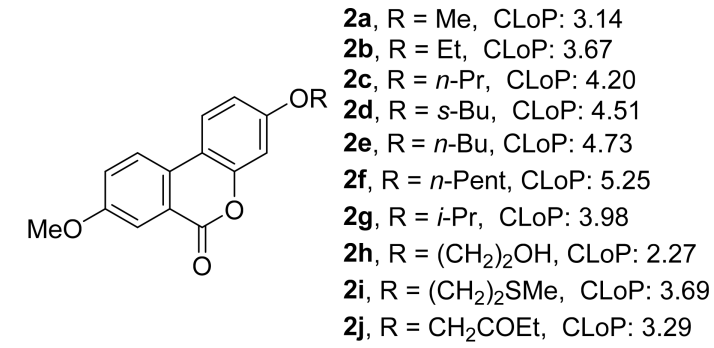<smiles>COc1ccc2c(c1)c(=O)oc1cc(OCC3CCCC3)ccc12</smiles>

2k, CLoP: 5.23<smiles>COc1ccc2c(c1)c(=O)oc1cc(OCC3CCCO3)ccc12</smiles>

2I, CLoP: 3.51<smiles>COc1ccc2c(c1)c(=O)oc1cc(OCC3OCCO3)ccc12</smiles>

2m, CLoP: 2.88<smiles>COc1ccc2c(c1)c(=O)oc1cc(OCC3CCCCC3)ccc12</smiles>

2n, CLoP: 5.39<smiles>COc1ccc2c(c1)c(=O)oc1cc(OCc3ccccc3)ccc12</smiles>

2q, CLoP: 4.91<smiles>COc1ccc2c(c1)c(=O)oc1cc(OCC3CCCCC3)ccc12</smiles>

2p, CLoP: 3.39<smiles>COc1cc(COc2ccc3c(c2)oc(=O)c2cc(OC)ccc23)cc(OC)c1</smiles>

2r, CLoP: 2.87 2s, CLoP: 4.92 2t, CLoP: 4.09<smiles>COc1ccc2c(c1)c(=O)oc1cc(OCc3cc(C)nn3C)ccc12</smiles>

1u, CLoP: 3.29

2v, CLoP: 2.77<smiles>COc1ccc2c(c1)c(=O)oc1cc(OCCn3cccn3)ccc12</smiles>

2w, CLoP: 3.23

Figure 2. CLoP values of $6 H$-benzo[c]chromen-6-one derivatives 2.

\subsection{Cell Assays}

Corticosterone can induce PDE2A, PDE3B, PDE4A, PDE4D, PDE10, and PDE11 expression in HT-22 cells, which results in significant cell lesion [30,31]. Thus, corticosteroneinduced HT-22 neurotoxicity was generally employed as classical cell model to screen PDE-inhibitors for curing neurodegenerative disease, such as AD and PD.

To determine whether compound $1 \mathrm{f}$ could promote neuron proliferation and protect HT-22 cells against corticosterone-induced neurotoxicity by PDE2 inhibition, the viability of HT-22 cells was measured in the presence of $100 \mu \mathrm{M}$ corticosterone (positive control), corticosterone absence (control), and different concentrations of 1f. As shown in Figure 3, the cell viability was significantly decreased when HT-22 cells were exposed to $100 \mu \mathrm{M}$ corticosterone $(p<0.001)$, which indicated that HT-22 neurotoxicity model was successfully built. Compound 1f significantly increased cell viability of HT-22 cells in a dose-dependent manner at concentration of $6.25 \sim 25 \mu \mathrm{M}$, and the best concentration was $12.5 \mu \mathrm{M}(p<0.01)$. In addition, the effect was similar with the BAY 60-7550 at a concentration of $1.0 \mu \mathrm{M}$. Our results showed compound $1 \mathrm{f}$ possessed good protective effects on HT-22 cells, which was associated with PDE2 inhibition. 
Table 1. In vitro PDE2 inhibitory activity of $6 H$-benzo[c]chromen-6-one derivatives 1 and 2.

\begin{tabular}{|c|c|c|c|}
\hline Compound & PDE2 $\mathrm{IC}_{50}{ }^{\mathrm{a}}(\mu \mathrm{M})$ & Compound & PDE2 $\mathrm{IC}_{50}{ }^{\mathrm{a}, \mathrm{b}}(\mu \mathrm{M})$ \\
\hline $1 a$ & $28.82 \pm 7.8$ & $2 a$ & $>50$ \\
\hline $1 b$ & $25.40 \pm 5.13$ & $2 b$ & $>50$ \\
\hline 1c & $25.80 \pm 5.45$ & $2 c$ & $>50$ \\
\hline 1d & $>50$ & $2 d$ & $>50$ \\
\hline 1e & $37.65 \pm 4.9$ & $2 e$ & $17.77 \pm 4.07$ \\
\hline 1f & $3.67 \pm 0.47$ & $2 f$ & $>50$ \\
\hline $1 \mathrm{~g}$ & $>50$ & $2 \mathrm{~g}$ & $30.29 \pm 7.38$ \\
\hline 1h & $18.69 \pm 2.72$ & $2 h$ & $>50$ \\
\hline $1 \mathrm{i}$ & $17.88 \pm 1.87$ & $2 \mathrm{i}$ & $14.88 \pm 1.78$ \\
\hline $\mathbf{1 j}$ & $43.22 \pm 3.67$ & $2 j$ & $>50$ \\
\hline $1 k$ & $>50$ & $2 k$ & $>50$ \\
\hline 11 & $19.27 \pm 2.38$ & 21 & $>50$ \\
\hline $1 \mathrm{~m}$ & $>50$ & $2 \mathrm{~m}$ & $>50$ \\
\hline 1n & $27.51 \pm 1.49$ & $2 n$ & $>50$ \\
\hline 10 & $>50$ & 20 & $>50$ \\
\hline $1 p$ & $>50$ & $2 p$ & $25.16 \pm 6.91$ \\
\hline $1 \mathrm{q}$ & $>50$ & $2 q$ & $23.31 \pm 4.28$ \\
\hline $1 \mathrm{r}$ & $27.56 \pm 2.14$ & $2 r$ & $>50$ \\
\hline 1s & $8.14 \pm 0.54$ & $2 s$ & $>50$ \\
\hline $1 t$ & $>50$ & $2 t$ & Insoluble \\
\hline \multirow[t]{3}{*}{$1 \mathbf{u}$} & $>50$ & $2 \mathbf{u}$ & $29.39 \pm 5.01$ \\
\hline & & $2 \mathbf{v}$ & $23.88 \pm 545$ \\
\hline & & $2 w$ & $>50$ \\
\hline
\end{tabular}

a BAY 60-7550 was used as the reference compound with an $\mathrm{IC}_{50}$ of $8.4 \mathrm{nM} \cdot{ }^{\mathrm{b}}$ Results are expressed as the mean of at least three experiments.

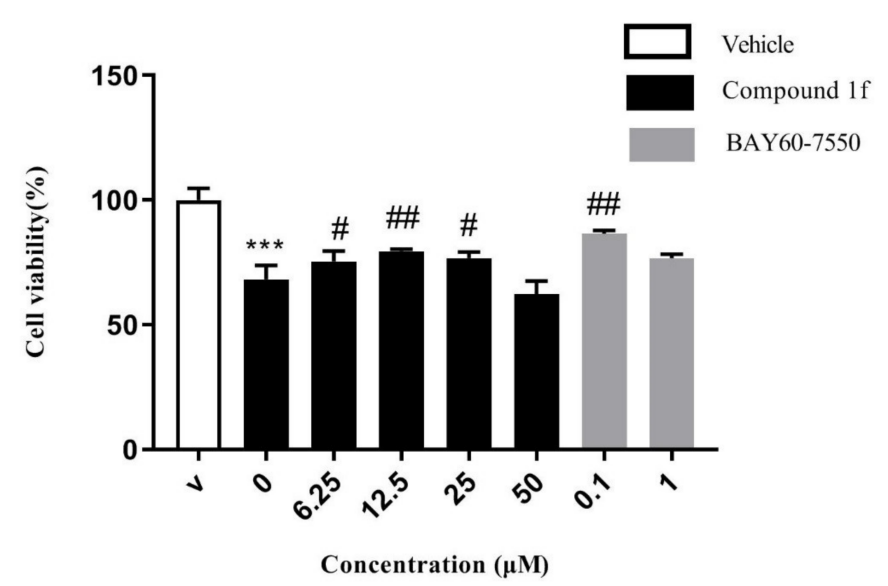

Figure 3. Compound $1 \mathrm{f}$ protected cells against corticosterone (CORT)-induced cytotoxicity in a concentration-dependent manner. HT-22 cells were treated with $100 \mathrm{M}$ CORT for $30 \mathrm{~min}$ and compound $1 \mathrm{f}$ was added for $24 \mathrm{~h}$. Cell viability was measured by MTS assay. Results are expressed as the mean \pm standard error of the mean (SEM) of six independent experiments performed in triplicates. *** $p<0.001$, compared to control group; \# $p<0.05$ and \#\# $p<0.01$, compared to vehicle-treated CORT group. 


\section{Experiments}

3.1. Synthesis

All chemicals, reagents, and solvents were analytical grade, purchased from commercial suppliers (i.e., Aladdin, Adamas, and Acros).

The reactions were monitored via thin-layer chromatography (TLC) performed on HSGF254 plates and visualized under UV light. Melting points were measured with an X4-A microscopic melting point apparatus. ${ }^{1} \mathrm{HNMR}$ spectra were recorded on a BrukerBioSpin $\mathrm{GmbH}$ spectrometer at 300 and $400 \mathrm{MHz} ;{ }^{13} \mathrm{CNMR}$ spectra were recorded on a BrukerBioSpin $\mathrm{GmbH}$ spectrometer at 75 and $100 \mathrm{MHz}$; the coupling constants are given in Hz. Mass (HRMS) analysis was obtained using Agilent 6200 Accurate-Mass TOF LC/MS system with Electrospray Ionization (ESI). HPLC analysis was obtained using SHIMADZULC-20AB.

\subsubsection{3-Hydroxy-6H-benzo[c]chromen-6-one (I)}

2-Bromobenzoic acid ( $30 \mathrm{mmol}, 6.03 \mathrm{~g}$ ), resorcinol $(60 \mathrm{mmol}, 6.60 \mathrm{~g})$, sodium hydroxide $(60 \mathrm{mmol}, 0.8 \mathrm{~g})$, and water $(30 \mathrm{~mL})$ were added in the $100 \mathrm{~mL}$ sealed tub, and the reaction was stirred $20 \mathrm{~min}$ at $100{ }^{\circ} \mathrm{C}$. Then, $5 \%$ copper sulfate solution $(9.6 \mathrm{~mL})$ was added to the system and heated to reflux for $1 \mathrm{~h}$. The progress of reaction was monitored through TLC (PE:EA = 5:1). At the end of the reaction, the reaction solution was added dropwise to the ice-water mixture, and the filtered solid continued to be washed with water. The filter cake was recrystallized twice with methanol and glacial acetic acid to obtain compound I (3.50 g, 55.0\%) [26]. M.p. $250-251{ }^{\circ} \mathrm{C} .{ }^{1} \mathrm{H}$ NMR (300 MHz, DMSO- $\left.d_{6}\right) \delta=10.36(\mathrm{~s}, 1 \mathrm{H}), 8.27$ $(\mathrm{dt}, J=8.0,3.0 \mathrm{~Hz}, 1 \mathrm{H}), 8.21-8.15(\mathrm{~m}, 2 \mathrm{H}), 7.89(\mathrm{~m}, 1 \mathrm{H}), 7.57(\mathrm{~m}, 1 \mathrm{H}), 6.85(\mathrm{dd}, J=9.0,3.0$ $\mathrm{Hz}, 1 \mathrm{H}), 6.76(\mathrm{~d}, J=3.0 \mathrm{~Hz}, 1 \mathrm{H}) ;{ }^{13} \mathrm{C}$ NMR $\left(75 \mathrm{MHz}, \mathrm{DMSO}-d_{6}\right) \delta=161.06,160.32,152.57$, 135.65, 135.52, 130.11, 128.04, 125.21, 122.02, 119.39, 113.60, 109.82, 103.40; HRMS (ESI) $\mathrm{m} / \mathrm{z}$ calcd for $\mathrm{C}_{13} \mathrm{H}_{9} \mathrm{O}_{3}{ }^{+}[\mathrm{M}+\mathrm{H}]^{+}$: 213.0473; found: 213.0470. Chromatographic purity: $98.0 \%$ (HPLC).

\subsubsection{General Procedures for Synthesis of Compounds 1a-u [28]}

The anhydrous DMF $(30 \mathrm{~mL}$ ) was added to a $250 \mathrm{~mL}$ round bottom flask, compound I (9.4 mmol, $2.0 \mathrm{~g})$, anhydrous $\mathrm{K}_{2} \mathrm{CO}_{3}(12.2 \mathrm{mmol}, 1.7 \mathrm{~g})$, and halide (12.2 mmol) were added, and the temperature was controlled at $80 \sim 120^{\circ} \mathrm{C}$; the reaction was stirred for $24 \mathrm{~h}$. The reaction was monitored by TLC (PE:EA = 3:1). When the reaction was over, the reaction solution was added to the ice-water mixture to obtain brown crude solid. After suction filtration and drying, the brown crude solid was purified by column chromatography to obtain compounds $1 \mathbf{a}-\mathbf{u}$.

3-Methoxy-6H-benzo[c]chromen-6-one (1a): Using iodomethane as the starting material, the desired white solid 1a was isolated $(1.30 \mathrm{~g}, 61 \%)$. M.p. $131.5-132.8{ }^{\circ} \mathrm{C} .{ }^{1} \mathrm{H}$ NMR $\left(400 \mathrm{MHz}, \mathrm{DMSO}-d_{6}\right) \delta=8.35(\mathrm{~d}, J=8.0 \mathrm{~Hz}, 1 \mathrm{H}), 8.29(\mathrm{~d}, J=12.0 \mathrm{~Hz}, 1 \mathrm{H}), 8.22(\mathrm{dd}$, $J=8.0 \mathrm{~Hz}, 1 \mathrm{H}), 7.95-7.90(\mathrm{~m}, 1 \mathrm{H}), 7.62(\mathrm{t}, J=6.0 \mathrm{~Hz}, 1 \mathrm{H}), 7.06-6.99(\mathrm{~m}, 2 \mathrm{H}), 3.88(\mathrm{~s}, 3 \mathrm{H}) ;{ }^{13} \mathrm{C}$ NMR $\left(100 \mathrm{MHz}\right.$, DMSO- $\left.d_{6}\right) \delta=161.67,160.96,152.54,135.78,135.19,130.14,128.53,125.17$, $122.40,119.68,112.78,111.09,101.91,56.23$; HRMS (ESI) $m / z$ calcd for $\mathrm{C}_{14} \mathrm{H}_{11} \mathrm{O}_{3}{ }^{+}[\mathrm{M}+\mathrm{H}]^{+}$: 227.0630; found: 227.0626. Chromatographic purity: 98.2\% (HPLC).

Ethoxy-6H-benzo[c]chromen-6-one (1b): Using bromoethane as the starting material, the desired yellow solid $\mathbf{1 b}$ was isolated $(1.70 \mathrm{~g}, 75 \%)$. M.p. $115.2-117.7^{\circ} \mathrm{C} .{ }^{1} \mathrm{H}$ NMR $(300 \mathrm{MHz}$, DMSO- $\left.d_{6}\right) \delta=8.35-8.22(\mathrm{~m}, 3 \mathrm{H}), 7.93(\mathrm{t}, J=6.0 \mathrm{~Hz}, 1 \mathrm{H}), 7.62(\mathrm{t}, J=6.0 \mathrm{~Hz}, 1 \mathrm{H}), 6.98$ $(\mathrm{d}, J=6.0 \mathrm{~Hz}, 2 \mathrm{H}), 4.13(\mathrm{q}, J=3.0 \mathrm{~Hz}, 2 \mathrm{H}), 1.39(\mathrm{t}, J=6.0 \mathrm{~Hz}, 3 \mathrm{H}) ;{ }^{13} \mathrm{C}$ NMR $(75 \mathrm{MHz}$, DMSO- $d_{6}$ ) $\delta=160.97,152.55,135.81,135.25,130.15,128.52,125.20,122.41,119.68,113.10$, $110.99,102.31,64.28,14.94$; HRMS (ESI) $\mathrm{m} / z$ calcd for $\mathrm{C}_{15} \mathrm{H}_{13} \mathrm{O}_{3}{ }^{+}[\mathrm{M}+\mathrm{H}]^{+}: 241.0786$; found: 241.0782. Chromatographic purity: $97.6 \%$ (HPLC).

3-Isopropoxy-6H-benzo[c]chromen-6-one (1c): Using 2-bromopropane as the starting material, the desired yellow solid $1 \mathrm{c}$ was isolated $(1.70 \mathrm{~g}, 71 \%)$. M.p. 58.7-59.1 ${ }^{\circ} \mathrm{C} .{ }^{1} \mathrm{H}$ NMR $\left(300 \mathrm{MHz}, \mathrm{DMSO}-d_{6}\right) \delta=8.68-7.33(\mathrm{~m}, 5 \mathrm{H}), 6.96(\mathrm{~s}, 2 \mathrm{H}), 4.77(\mathrm{~m}, 1 \mathrm{H}), 1.32(\mathrm{~d}, J=6.0 \mathrm{~Hz}$, 
$6 \mathrm{H}) ;{ }^{13} \mathrm{C}$ NMR $\left(75 \mathrm{MHz}, \mathrm{DMSO}-d_{6}\right) \delta=160.98,159.92,152.59,135.76,135.23,130.13$, $128.45,125.22,122.34,119.65,113.83,110.83,103.23,70.42,22.13$; HRMS (ESI) $m / z$ calcd for $\mathrm{C}_{16} \mathrm{H}_{15} \mathrm{O}_{3}{ }^{+}[\mathrm{M}+\mathrm{H}]^{+}:$255.0943; found: 255.0940. Chromatographic purity: 97.8\% (HPLC).

3-Propoxy-6H-benzo[c]chromen-6-one (1d): Using 1-bromopropane as the starting material, the desired white solid $1 \mathrm{~d}$ was isolated $(1.99 \mathrm{~g}, 83 \%)$. M.p. $67.6-69.2{ }^{\circ} \mathrm{C} .{ }^{1} \mathrm{H}$ NMR $\left(300 \mathrm{MHz}, \mathrm{DMSO}-d_{6}\right) \delta=8.28(\mathrm{t}, J=6.0 \mathrm{~Hz}, 1 \mathrm{H}), 8.23-8.17(\mathrm{~m}, 2 \mathrm{H}), 7.92-7.86(\mathrm{~m}, 1 \mathrm{H})$, 7.61-7.55 (m, 1H), 6.99-6.93 (m, 2H), 4.04-3.99 (m,2H), 1.83-1.71 (m, 2H), $1.01(\mathrm{t}, J=6.0 \mathrm{~Hz}$, $3 \mathrm{H}) ;{ }^{13} \mathrm{C}$ NMR $\left(75 \mathrm{MHz}, \mathrm{DMSO}-d_{6}\right) \delta=161.07,160.95,152.50,135.74,135.21,130.11$, 128.46,125.12, 122.35,119.64, 113.06, 110.95,102.29, 70.00, 22.35, 10.80; HRMS (ESI) $m / z$ calcd for $\mathrm{C}_{16} \mathrm{H}_{15} \mathrm{O}_{3}{ }^{+}[\mathrm{M}+\mathrm{H}]^{+}:$255.0943; found: 255.0940 . Chromatographic purity: $98.9 \%$ (HPLC).

3-(Sec-butoxy)-6H-benzo[c]chromen-6-one (1e): Using 2-bromobutane as the starting material, the desired yellow solid 1e was isolated $(1.79 \mathrm{~g}, 71 \%)$. M.p. $73.2-75.8^{\circ} \mathrm{C}$. ${ }^{1} \mathrm{H}$ NMR $\left(400 \mathrm{MHz}\right.$, DMSO- $\left.d_{6}\right) \delta=8.36-8.19(\mathrm{~m}, 3 \mathrm{H}), 7.93-7.88(\mathrm{~m}, 1 \mathrm{H}), 7.62-7.57(\mathrm{~m}, 1 \mathrm{H}), 7.00-6.97$ $(\mathrm{m}, 2 \mathrm{H}), 4.60-4.53(\mathrm{~m}, 1 \mathrm{H}), 1.74-1.58(\mathrm{~m}, 2 \mathrm{H}), 1.28(\mathrm{~d}, J=8.0 \mathrm{~Hz}, 3 \mathrm{H}), 0.95(\mathrm{t}, J=4.0 \mathrm{~Hz}, 3 \mathrm{H})$; ${ }^{13} \mathrm{C}$ NMR $\left(100 \mathrm{MHz}, \mathrm{DMSO}-d_{6}\right) \delta=160.97,160.25,152.58,135.73,135.24,130.12,128.41$, $125.19,122.31,119.64,113.83,110.83,103.21,75.23,28.89,19.35,9.92$; HRMS (ESI) $m / z$ calcd for $\mathrm{C}_{17} \mathrm{H}_{17} \mathrm{O}_{3}{ }^{+}[\mathrm{M}+\mathrm{H}]^{+}:$: 269.1099; found: 269.1095 . Chromatographic purity: $99.2 \%$ (HPLC).

3-Butoxy-6H-benzo[c]chromen-6-one (1f): Using 1-bromobutane as the starting material, the desired yellow solid $1 \mathrm{f}$ was isolated $(1.41 \mathrm{~g}, 56 \%)$. M.p. 53.6-55.5 ${ }^{\circ} \mathrm{C} .{ }^{1} \mathrm{H}$ NMR $(300 \mathrm{MHz}$, DMSO- $\left.d_{6}\right) \delta=8.34-8.20(\mathrm{~m}, 3 \mathrm{H}), 7.91(\mathrm{t}, J=9.0 \mathrm{~Hz}, 1 \mathrm{H}), 7.60(\mathrm{t}, J=9.0 \mathrm{~Hz}, 1 \mathrm{H}), 7.01-6.99$ $(\mathrm{d}, J=6.0 \mathrm{~Hz}, 2 \mathrm{H}), 4.09(\mathrm{t}, J=6.0 \mathrm{~Hz}, 2 \mathrm{H}), 1.74(\mathrm{t}, J=9.0 \mathrm{~Hz}, 2 \mathrm{H}), 1.50-1.42(\mathrm{~m}, 2 \mathrm{H}), 0.95$ $(\mathrm{t}, J=9.0 \mathrm{~Hz}, 3 \mathrm{H}) ;{ }^{13} \mathrm{C}$ NMR $\left(75 \mathrm{MHz}, \mathrm{DMSO}-d_{6}\right) \delta=161.13,160.98,152.54,135.78,135.25$, $130.14,128.49,125.16,122.39,119.67,113.13,110.98,102.34,68.30,31.03,19.17,14.15$; HRMS (ESI) $\mathrm{m} / z$ calcd for $\mathrm{C}_{17} \mathrm{H}_{17} \mathrm{O}_{3}{ }^{+}[\mathrm{M}+\mathrm{H}]^{+}$: 269.1099; found: 269.1095. Chromatographic purity: 98.7\% (HPLC).

3-(Pentyloxy)-6H-benzo[c]chromen-6-one (1g): Using 1-bromopentane as the starting material, the desired yellow solid $1 \mathrm{~g}$ was isolated $(1.49 \mathrm{~g}, 56 \%)$. M.p. $69.4-71.8^{\circ} \mathrm{C}$. ${ }^{1} \mathrm{H}$ NMR $\left(400 \mathrm{MHz}\right.$, DMSO- $\left.d_{6}\right) \delta=8.34-8.20(\mathrm{~m}, 3 \mathrm{H}), 7.91(\mathrm{t}, J=8.0 \mathrm{~Hz}, 1 \mathrm{H}), 7.60(\mathrm{t}, J=8.0 \mathrm{~Hz}, 1 \mathrm{H})$, 7.01-6.98 (m, 2H), $4.08(\mathrm{t}, J=6.0 \mathrm{~Hz}, 2 \mathrm{H}), 1.79-1.72(\mathrm{~m}, 2 \mathrm{H}), 1.46-1.32(\mathrm{~m}, 4 \mathrm{H}), 0.91(\mathrm{t}$, $J=8.0 \mathrm{~Hz}, 3 \mathrm{H}) ;{ }^{13} \mathrm{C}$ NMR $\left(100 \mathrm{MHz}, \mathrm{DMSO}-d_{6}\right) \delta=161.10,160.97,153.65,135.77,135.23$, 130.13, 128.47, 125.14, 122.37, 119.66, 113.10, 110.95, 103.11, 68.56, 29.42, 28.12, 22.36, 17.18; HRMS (ESI) $m / z$ calcd for $\mathrm{C}_{18} \mathrm{H}_{19} \mathrm{O}_{3}{ }^{+}[\mathrm{M}+\mathrm{H}]^{+}$: 283.1256; found: 283.1252. Chromatographic purity: $99.2 \%$ (HPLC).

Ethyl 2-((6-oxo-6H-benzo[c]chromen-3-yl)oxy)acetate (1h): Using ethyl 2-bromoacetate as the starting material, the desired yellow solid $1 \mathrm{~h}$ was isolated $(1.40 \mathrm{~g}, 50 \%)$. M.p. 124.7-125.8 ${ }^{\circ} \mathrm{C} .{ }^{1} \mathrm{H}$ NMR $\left(300 \mathrm{MHz}\right.$, DMSO- $\left.d_{6}\right) \delta=8.36-8.21(\mathrm{~m}, 3 \mathrm{H}), 7.93(\mathrm{t}, J=7.5 \mathrm{~Hz}, 1 \mathrm{H})$, $7.62(\mathrm{t}, J=7.5 \mathrm{~Hz}, 1 \mathrm{H}), 7.04(\mathrm{dt}, J=9.0,3.0 \mathrm{~Hz}, 2 \mathrm{H}), 4.94(\mathrm{~s}, 2 \mathrm{H}), 4.20(\mathrm{q}, J=7.0 \mathrm{~Hz}, 2 \mathrm{H}), 1.24$ $(\mathrm{t}, J=7.5 \mathrm{~Hz}, 3 \mathrm{H}) ;{ }^{13} \mathrm{C}$ NMR $\left(75 \mathrm{MHz}\right.$, DMSO- $\left.d_{6}\right) \delta=168.79,160.88,159.94,152.37,136.32$, $135.03,130.17,128.74,125.29,122.52,120.20,113.06,111.79,103.34,66.14,62.31,15.96$; HRMS (ESI) $\mathrm{m} / z$ calcd for $\mathrm{C}_{17} \mathrm{H}_{15} \mathrm{O}_{5}{ }^{+}[\mathrm{M}+\mathrm{H}]^{+}$: 299.0841; found: 299.0837. Chromatographic purity: 98.3\% (HPLC).

3-((Tetrahydro-2H-pyran-4-yl)methoxy)-6H-benzo[c]chromen-6-one (1i): Using 4(bromomethyl)tetrahydro-2H-pyran as the starting material, the desired yellow solid $1 \mathbf{i}$ was isolated (1.60 g, 55\%). M.p. 133.0-134.8 ${ }^{\circ} \mathrm{C} .{ }^{1} \mathrm{H}$ NMR $\left(300 \mathrm{MHz}, \mathrm{CDCl}_{3}\right) \delta=8.34(\mathrm{~d}$, $J=9.0 \mathrm{~Hz}, 1 \mathrm{H}), 7.96(\mathrm{dd}, J=18.0,9.0 \mathrm{~Hz}, 2 \mathrm{H}), 7.78(\mathrm{t}, J=7.5 \mathrm{~Hz}, 1 \mathrm{H}), 7.50(\mathrm{t}, J=7.5 \mathrm{~Hz}, 1 \mathrm{H})$, 6.91-6.82 (m, 2H), $4.04(\mathrm{dd}, J=12.0,9.0 \mathrm{~Hz}, 2 \mathrm{H}), 3.87(\mathrm{t}, J=6.0 \mathrm{~Hz}, 2 \mathrm{H}), 3.46(\mathrm{t}, J=12.0 \mathrm{~Hz}$, $2 \mathrm{H}), 2.17-2.06(\mathrm{~m}, 1 \mathrm{H}), 1.80(\mathrm{~d}, J=3.0 \mathrm{~Hz}, 2 \mathrm{H}), 1.57-4.13(\mathrm{~m}, 2 \mathrm{H}) ;{ }^{13} \mathrm{C}$ NMR $(75 \mathrm{MHz}$, DMSO$\left.d_{6}\right) \delta=161.09,160.97,152.53,135.79,135.22,130.15,128.53,125.19,122.41,119.69,113.13$, $111.08,102.44,73.00,67.06,34.77,29.60$; HRMS (ESI) $m / z$ calcd for $\mathrm{C}_{19} \mathrm{H}_{19} \mathrm{O}_{4}{ }^{+}[\mathrm{M}+\mathrm{H}]^{+}$: 311.1205; found: 311.1201. Chromatographic purity: 97.3\% (HPLC). 
3-(Benzyloxy)-6H-benzo[c]chromen-6-one (1j): Using (bromomethyl)benzene as the starting material, the desired yellow solid $1 \mathrm{j}$ was isolated $(2.81 \mathrm{~g}, 99 \%)$. M.p. $113.2-115.3^{\circ} \mathrm{C}$. ${ }^{1} \mathrm{H}$ NMR $\left(300 \mathrm{MHz}\right.$, DMSO- $\left.d_{6}\right) \delta=8.31(\mathrm{dd}, J=15.0,9.0 \mathrm{~Hz}, 2 \mathrm{H}), 8.21(\mathrm{dd}, J=9.0,1.2 \mathrm{~Hz}$, $1 \mathrm{H}), 7.94-7.89(\mathrm{~m}, 1 \mathrm{H}), 7.61-7.58(\mathrm{~m}, 1 \mathrm{H}), 7.52-7.48(\mathrm{~m}, 2 \mathrm{H}), 7.45-7.35(\mathrm{~m}, 3 \mathrm{H}), 7.12-7.07$ $(\mathrm{m}, 2 \mathrm{H}), 5.24(\mathrm{~s}, 2 \mathrm{H}) ;{ }^{13} \mathrm{C}$ NMR $\left(75 \mathrm{MHz}, \mathrm{DMSO}-d_{6}\right) \delta=160.95,160.70,152.48,136.92$, 135.81, 135.17, 130.16, 128.99, 128.61, 128.53, 128.37, 125.26, 122.47, 119.76, 113.44, 111.34, 102.91, 70.25; HRMS (ESI) $m / z$ calcd for $\mathrm{C}_{20} \mathrm{H}_{15} \mathrm{O}_{3}{ }^{+}[\mathrm{M}+\mathrm{H}]^{+}:$303.0943; found: 303.0940 . Chromatographic purity: $96.8 \%$ (HPLC).

3-(2-(1H-pyrazol-1-yl)ethoxy)-6H-benzo[c]chromen-6-one (1k): Using 1-(2-bromoethyl)-1Hpyrazole as the starting material, the desired white solid $\mathbf{1 k}$ was isolated $(1.24 \mathrm{~g}, 43 \%)$. M.p. $164.3-166.6{ }^{\circ} \mathrm{C} .{ }^{1} \mathrm{H}$ NMR $\left(300 \mathrm{MHz}, \mathrm{DMSO}-d_{6}\right) \delta=8.32(\mathrm{~d}, J=9.0 \mathrm{~Hz}, 1 \mathrm{H}), 8.27-8.19$ $(\mathrm{m}, 2 \mathrm{H}), 7.93-7.88(\mathrm{~m}, 1 \mathrm{H}), 7.82(\mathrm{~d}, J=2.1 \mathrm{~Hz}, 1 \mathrm{H}), 7.63-7.57(\mathrm{~m}, 1 \mathrm{H}), 7.48(\mathrm{~d}, J=3.0 \mathrm{~Hz}$, $1 \mathrm{H}), 7.01-6.95(\mathrm{~m}, 2 \mathrm{H}), 6.27(\mathrm{t}, J=3.0 \mathrm{~Hz}, 1 \mathrm{H}), 4.55(\mathrm{~m}, 2 \mathrm{H}), 4.46(\mathrm{~m}, 2 \mathrm{H}) ;{ }^{13} \mathrm{C}$ NMR $\left(75 \mathrm{MHz}\right.$, DMSO- $\left.d_{6}\right) \delta=160.94,160.43,152.48,139.39,135.84,135.12,131.08,130.17,128.67$, $125.29,122.49,119.77,113.16,111.46,105.72,102.63,67.60,50.93$; HRMS (ESI) $\mathrm{m} / \mathrm{z}$ calcd for $\mathrm{C}_{18} \mathrm{H}_{15} \mathrm{~N}_{2} \mathrm{O}_{3}{ }^{+}[\mathrm{M}+\mathrm{H}]^{+}$: 307.1004; found: 307.1001 . Chromatographic purity: $96.5 \%$ (HPLC).

3-(Pyrimidin-2-yloxy)-6H-benzo[c]chromen-6-one (11): Using 2-bromopyrimidine as the starting material, the desired yellow solid 11 was isolated (1.83 g, 67\%). M.p. $174.0-176.6{ }^{\circ} \mathrm{C}$. ${ }^{1} \mathrm{H}$ NMR $\left(400 \mathrm{MHz}\right.$, DMSO- $\left.d_{6}\right) \delta=8.70(\mathrm{~d}, J=8.0 \mathrm{~Hz}, 2 \mathrm{H}), 8.45(\mathrm{~d}, J=8.0 \mathrm{~Hz}, 2 \mathrm{H}), 8.28$ $(\mathrm{d}, J=12.0 \mathrm{~Hz}, 1 \mathrm{H}), 7.98(\mathrm{t}, J=10.0 \mathrm{~Hz}, 1 \mathrm{H}), 7.70(\mathrm{t}, J=10.0 \mathrm{~Hz}, 1 \mathrm{H}), 7.41-7.29(\mathrm{~m}$, $3 \mathrm{H}) ;{ }^{13} \mathrm{C}$ NMR $\left(100 \mathrm{MHz}, \mathrm{DMSO}-d_{6}\right) \delta=164.80,160.66,154.69,151.92,135.92,134.55$, 130.26, 129.58, 125.31, 123.09, 120.57, 119.02, 117.93, 115.50, 111.00; HRMS (ESI) $\mathrm{m} / \mathrm{z}$ calcd for $\mathrm{C}_{17} \mathrm{H}_{11} \mathrm{~N}_{2} \mathrm{O}_{3}{ }^{+}[\mathrm{M}+\mathrm{H}]^{+}$: 291.0691; found: 291.0686. Chromatographic purity: $98.2 \%$ (HPLC).

3-(2-Hydroxyethoxy)-6H-benzo[c]chromen-6-one (1m): Using 2-bromoethanol as the starting material, the desired white solid $1 \mathrm{~m}$ was isolated (2.34 g, 98\%). M.p. $125.7-126.4^{\circ} \mathrm{C}$. ${ }^{1} \mathrm{H}$ NMR $\left(400 \mathrm{MHz}\right.$, DMSO- $\left.d_{6}\right) \delta=8.32(\mathrm{~d}, J=8.0 \mathrm{~Hz}, 1 \mathrm{H}), 8.27-8.24(\mathrm{~m}, 1 \mathrm{H}), 8.21(\mathrm{dd}$, $J=8.0,4.0 \mathrm{~Hz}, 1 \mathrm{H}), 7.94-7.90(\mathrm{~m}, 1 \mathrm{H}), 7.61(\mathrm{t}, J=8.0 \mathrm{~Hz}, 1 \mathrm{H}), 7.03-7.00(\mathrm{~m}, 2 \mathrm{H}), 5.01$ $(\mathrm{t}, J=6.0 \mathrm{~Hz}, 1 \mathrm{H}), 4.11(\mathrm{t}, J=4.0 \mathrm{~Hz}, 2 \mathrm{H}), 3.76(\mathrm{q}, J=4.0 \mathrm{~Hz}, 2 \mathrm{H}) ;{ }^{13} \mathrm{C} \mathrm{NMR}(100 \mathrm{MHz}$, DMSO- $\left.d_{6}\right) \delta=161.16,161.07,152.52,135.90,135.23,130.19,128.61,125.23,122.42,119.67$, 113.25, 111.05, 102.43, 70.65, 59.87; HRMS (ESI) $m / z$ calcd for $\mathrm{C}_{15} \mathrm{H}_{13} \mathrm{O}_{4}{ }^{+}[\mathrm{M}+\mathrm{H}]^{+}:$: 257.0736; found: 257.0732. Chromatographic purity: 98.3\% (HPLC).

3-((Tetrahydrofuran-2-yl)methoxy)-6H-benzo[c]chromen-6-one (1n): Using 2(bromomethyl)tetrahydrofuran as the starting material, the desired yellow solid 1 n was isolated $(1.31 \mathrm{~g}, 47 \%)$. M.p. $82.8-84.1^{\circ} \mathrm{C} .{ }^{1} \mathrm{H}$ NMR $\left(400 \mathrm{MHz}, \mathrm{CDCl}_{3}\right) \delta=8.36(\mathrm{~d}, J=8.0 \mathrm{~Hz}$, $1 \mathrm{H}), 8.00(\mathrm{~d}, J=8.0 \mathrm{~Hz}, 1 \mathrm{H}), 7.94(\mathrm{~d}, J=8.0 \mathrm{~Hz}, 1 \mathrm{H}), 7.79(\mathrm{t}, J=8.0 \mathrm{~Hz}, 1 \mathrm{H}), 7.51(\mathrm{t}, J=8.0 \mathrm{~Hz}$, $1 \mathrm{H}), 6.96(\mathrm{dd}, J=8.0,4.0 \mathrm{~Hz}, 1 \mathrm{H}), 6.89(\mathrm{~d}, J=4.0 \mathrm{~Hz}, 1 \mathrm{H}), 4.37-4.30(\mathrm{~m}, 1 \mathrm{H}), 4.08-3.95$ $(\mathrm{m}, 3 \mathrm{H}), 3.91-3.85(\mathrm{q}, J=8.0 \mathrm{~Hz}, 1 \mathrm{H}), 2.18-2.09(\mathrm{~m}, 1 \mathrm{H}), 2.06-1.94(\mathrm{~m}, 2 \mathrm{H}), 1.85-1.76(\mathrm{~m}$, $1 \mathrm{H}) ;{ }^{13} \mathrm{C} \mathrm{NMR}\left(100 \mathrm{MHz}, \mathrm{CDCl}_{3}\right) \delta=161.55,160.74,152.49,135.15,134.88,130.54,127.76$, $123.77,121.11,119.97,112.90,111.28,102.27,76.85,70.86,68.72,28.19,25.76$; HRMS (ESI) $m / z$ calcd for $\mathrm{C}_{18} \mathrm{H}_{17} \mathrm{O}_{4}{ }^{+}[\mathrm{M}+\mathrm{H}]^{+}: 297.1049$; found: 297.1045. Chromatographic purity: 99.1\% (HPLC).

3-((1,3-Dioxolan-2-yl)methoxy)-6H-benzo[c]chromen-6-one (10): Using 2-(bromomethyl)-1,3dioxolane as the starting material, the desired white solid 10 was isolated $1.93 \mathrm{~g}, 69 \%$ ). M.p. $135.6-137.8{ }^{\circ} \mathrm{C} .{ }^{1} \mathrm{H}$ NMR $\left(400 \mathrm{MHz}, \mathrm{CDCl}_{3}\right) \delta=8.35(\mathrm{~d}, J=8.0 \mathrm{~Hz}, 1 \mathrm{H}), 8.00(\mathrm{~d}$, $J=8.0 \mathrm{~Hz}, 1 \mathrm{H}), 7.94(\mathrm{~d}, J=8.0 \mathrm{~Hz}, 1 \mathrm{H}), 7.81-7.77(\mathrm{~m}, 1 \mathrm{H}), 7.51(\mathrm{t}, J=8.0 \mathrm{~Hz}, 1 \mathrm{H}), 6.96$ $(\mathrm{dd}, J=12.0,4.0 \mathrm{~Hz}, 1 \mathrm{H}), 6.90(\mathrm{~d}, J=4.0 \mathrm{~Hz}, 1 \mathrm{H}), 5.34(\mathrm{t}, J=4.0 \mathrm{~Hz}, 1 \mathrm{H}), 4.14-3.96(\mathrm{~m}$, $6 \mathrm{H}) ;{ }^{13} \mathrm{C} \mathrm{NMR}\left(100 \mathrm{MHz}, \mathrm{CDCl}_{3}\right) \delta=161.45,160.29,152.43,135.02,134.90,130.54,127.86$, $123.84,121.14,120.01,112.74,111.61,102.49,101.66,69.01,65.41$; HRMS (ESI) $m / z$ calcd for $\mathrm{C}_{17} \mathrm{H}_{15} \mathrm{O}_{5}^{+}[\mathrm{M}+\mathrm{H}]^{+}:$299.0841; found: 299.0839. Chromatographic purity: 98.6\% (HPLC). 
3-((3,5-Dimethoxybenzyl)oxy)-6H-benzo[c]chromen-6-one (1p): Using 1-(bromomethyl)-3,5dimethoxybenzene as the starting material, the desired white solid $1 \mathbf{p}$ was isolated ( $3.37 \mathrm{~g}$, 99\%). M.p. $133.8-135.0{ }^{\circ} \mathrm{C} .{ }^{1} \mathrm{H}$ NMR $\left(300 \mathrm{MHz}, \mathrm{DMSO}-d_{6}\right) \delta=8.23-8.11(\mathrm{~m}, 3 \mathrm{H}), 7.82(\mathrm{t}$, $J=9.0 \mathrm{~Hz}, 1 \mathrm{H}), 7.52(\mathrm{t}, J=7.5 \mathrm{~Hz}, 1 \mathrm{H}), 7.00-6.97(\mathrm{~m}, 2 \mathrm{H}), 6.58(\mathrm{~d}, J=3.0 \mathrm{~Hz}, 2 \mathrm{H}), 6.40(\mathrm{t}$, $J=3.0 \mathrm{~Hz}, 1 \mathrm{H}), 5.09(\mathrm{~s}, 2 \mathrm{H}), 3.68(\mathrm{~s}, 6 \mathrm{H}) ;{ }^{13} \mathrm{C}$ NMR $\left(75 \mathrm{MHz}, \mathrm{DMSO}-d_{6}\right) \delta=161.03,160.94$, $160.56,152.43,139.24,135.76,135.13,130.13,128.58,125.22,122.43,119.73,113.39,111.34$, 106.01, 102.87, 99.98, 70.04, 55.65; HRMS (ESI) $\mathrm{m} / z$ calcd for $\mathrm{C}_{22} \mathrm{H}_{19} \mathrm{O}_{5}{ }^{+}[\mathrm{M}+\mathrm{H}]^{+}$: 363.1154; found: 363.1151. Chromatographic purity: $98.4 \%$ (HPLC).

3-((1,3-Dimethyl-1H-pyrazol-5-yl)methoxy)-6H-benzo[c]chromen-6-one (1q): Using 5(bromomethyl)-1,3-dimethyl-1H-pyrazole as the starting material, the desired whitesolid 1q was isolated (2.92 g, 97\%). M.p. 165.1-167.6 ${ }^{\circ} \mathrm{C} .{ }^{1} \mathrm{H} \mathrm{NMR}\left(300 \mathrm{MHz}, \mathrm{CDCl}_{3}\right) \delta=8.34(\mathrm{dd}$, $J=9.0,1.5 \mathrm{~Hz}, 1 \mathrm{H}), 8.00-7.93(\mathrm{~m}, 2 \mathrm{H}), 7.82-7.76(\mathrm{~m}, 1 \mathrm{H}), 7.54-7.49(\mathrm{~m}, 1 \mathrm{H}), 6.95(\mathrm{~m}, 2 \mathrm{H})$, $6.16(\mathrm{~s}, 1 \mathrm{H}), 5.07(\mathrm{~s}, 2 \mathrm{H}), 3.87(\mathrm{~s}, 3 \mathrm{H}), 2.26(\mathrm{~s}, 3 \mathrm{H}) ;{ }^{13} \mathrm{C}$ NMR $\left(75 \mathrm{MHz}, \mathrm{CDCl}_{3}\right) \delta=161.39$, 159.70, 152.41, 147.46, 136.99, 134.98, 134.89, 130.57, 128.02, 124.00, 121.17, 120.01, 112.96, $111.84,107.14,102.50,60.81,36.53,13.44$; HRMS (ESI) $m / z$ calcd for $\mathrm{C}_{19} \mathrm{H}_{17} \mathrm{~N}_{2} \mathrm{O}_{3}{ }^{+}[\mathrm{M}+\mathrm{H}]^{+}$: 321.1161; found: 321.1158. Chromatographic purity: 97.1\% (HPLC).

3-(Pyridin-3-ylmethoxy)-6H-benzo[c]chromen-6-one (1r): Using 3-(bromomethyl)pyridine as the starting material, the desired yellow solid $1 \mathbf{r}$ was isolated $(1.42 \mathrm{~g}, 50 \%)$. M.p. 143.6-145.3 ${ }^{\circ} \mathrm{C} .{ }^{1} \mathrm{H}$ NMR $\left(300 \mathrm{MHz}, \mathrm{CDCl}_{3}\right) \delta=8.69(\mathrm{~d}, J=30.0 \mathrm{~Hz}, 2 \mathrm{H}), 8.35(\mathrm{dd}, J=9.0$, $3.0 \mathrm{~Hz}, 1 \mathrm{H}), 7.98(\mathrm{dd}, J=12.0,6.0 \mathrm{~Hz}, 2 \mathrm{H}), 7.853-7.76(\mathrm{~m}, 2 \mathrm{H}), 7.51(\mathrm{t}, J=7.5 \mathrm{~Hz}, 1 \mathrm{H}), 7.37$ $(\mathrm{dd}, J=9.0,3.0 \mathrm{~Hz}, 1 \mathrm{H}), 6.98(\mathrm{dd}, J=9.0,3.0 \mathrm{~Hz}, 1 \mathrm{H}), 6.97(\mathrm{~d}, J=3.0 \mathrm{~Hz}, 1 \mathrm{H}), 5.15(\mathrm{~s}, 2 \mathrm{H})$; ${ }^{13} \mathrm{C}$ NMR $\left(75 \mathrm{MHz}, \mathrm{CDCl}_{3}\right) \delta=161.39,160.06,152.50,149.79,149.07,135.42,134.95,134.10$, $131.74,130.58,127.97,124.00,123.65,121.17,120.03,112.92,111.75,102.64,67.94$; HRMS (ESI) $\mathrm{m} / z$ calcd for $\mathrm{C}_{19} \mathrm{H}_{14} \mathrm{NO}_{3}{ }^{+}[\mathrm{M}+\mathrm{H}]^{+}$: 304.0895; found: 304.0891. Chromatographic purity: $96.2 \%$ (HPLC).

3-(Cyclopentylmethoxy)-6H-benzo[c]chromen-6-one (1s): Using (bromomethyl)cyclopentane as the starting material, the desired yellow solid 1s was isolated $(2.13 \mathrm{~g}, 77 \%)$. M.p. 90.6-91.2 ${ }^{\circ} \mathrm{C} .{ }^{1} \mathrm{H} \mathrm{NMR}\left(300 \mathrm{MHz}, \mathrm{CDCl}_{3}\right) \delta=8.34(\mathrm{dd}, J=9.0,1.5 \mathrm{~Hz}, 1 \mathrm{H}), 7.98(\mathrm{dd}, J=6.0$, $1.2 \mathrm{~Hz}, 1 \mathrm{H}), 7.91(\mathrm{~d}, J=9.0 \mathrm{~Hz}, 1 \mathrm{H}), 7.79-7.74(\mathrm{~m}, 1 \mathrm{H}), 7.51-7.45(\mathrm{~m}, 1 \mathrm{H}), 6.90(\mathrm{dd}, J=9.0$, $3.0 \mathrm{~Hz}, 1 \mathrm{H}), 6.83(\mathrm{~d}, J=3.0 \mathrm{~Hz}, 1 \mathrm{H}), 3.89(\mathrm{~d}, J=6.0 \mathrm{~Hz}, 2 \mathrm{H}), 2.47(\mathrm{~m}, 1 \mathrm{H}), 1.96-1.79(\mathrm{~m}, 2 \mathrm{H})$, $1.752-1.55(\mathrm{~m}, 4 \mathrm{H}), 1.44-1.32(\mathrm{~m}, 2 \mathrm{H}) ;{ }^{13} \mathrm{C}$ NMR $\left(75 \mathrm{MHz}, \mathrm{CDCl}_{3}\right) \delta=161.61,161.19,152.56$, $135.25,134.85,130.52,127.61,123.67,121.05,119.89,112.87,110.87,102.12,72.67,38.90$, 29.48, 25.45; HRMS (ESI) $m / z$ calcd for $\mathrm{C}_{19} \mathrm{H}_{19} \mathrm{O}_{3}{ }^{+}[\mathrm{M}+\mathrm{H}]^{+}:$295.1256; found: 295.1251 . Chromatographic purity: $98.4 \%$ (HPLC).

3-((4-[Hydroxymethyl]benzyl)oxy)-6H-benzo[c]chromen-6-one

$(\mathbf{1 t})$ :

Using (4-(bromomethyl)phenyl)methanol as the starting material, the desired white solid $\mathbf{1 t}$ was isolated (2.40 g, 77\%). M.p. 147.0-149.2 ${ }^{\circ} \mathrm{C} .{ }^{1} \mathrm{H}$ NMR $\left(300 \mathrm{MHz}, \mathrm{DMSO}-d_{6}\right) \delta=8.33(\mathrm{~d}$, $J=9.0 \mathrm{~Hz}, 1 \mathrm{H}), 8.29-8.21(\mathrm{~m}, 2 \mathrm{H}), 7.96-7.90(\mathrm{~m}, 1 \mathrm{H}), 7.65-7.60(\mathrm{~m}, 1 \mathrm{H}), 7.49(\mathrm{~d}, J=9.0 \mathrm{~Hz}$, 2H), $7.40(\mathrm{~d}, J=9.0 \mathrm{~Hz}, 2 \mathrm{H}), 7.12-7.07(\mathrm{~m}, 2 \mathrm{H}), 5.29(\mathrm{t}, J=9.0 \mathrm{~Hz}, 1 \mathrm{H}), 5.24(\mathrm{~s}, 2 \mathrm{H}), 4.55$ $(\mathrm{d}, J=6.0 \mathrm{~Hz}, 2 \mathrm{H}) ;{ }^{13} \mathrm{C}$ NMR $\left(75 \mathrm{MHz}\right.$, DMSO- $\left.d_{6}\right) \delta=160.95,160.68,152.45,142.94,135.79$, 135.17, 130.15, 128.58, 128.24, 127.02, 125.21, 122.44, 119.72, 113.45, 111.27, 102.87, 70.14, 63.10; HRMS (ESI) $\mathrm{m} / z$ calcd for $\mathrm{C}_{21} \mathrm{H}_{17} \mathrm{O}_{4}{ }^{+}[\mathrm{M}+\mathrm{H}]^{+}: 333.1049$; found: 333.1044.Chromatographic purity: $97.2 \%$ (HPLC).

3-(2-Morpholinoethoxy)-6H-benzo[c]chromen-6-one (1u): Using 4-(2-bromoethyl)morpholine as the starting material, the desired yellow solid $1 \mathbf{u}$ was isolated $(1.22 \mathrm{~g}, 40 \%)$. M.p. 100.8-102.8 ${ }^{\circ} \mathrm{C} .{ }^{1} \mathrm{H}$ NMR $\left(300 \mathrm{MHz}, \mathrm{CDCl}_{3}\right) \delta=8.35(\mathrm{dd}, J=9.0,1.2 \mathrm{~Hz}, 1 \mathrm{H}), 7.96(\mathrm{dd}$, $J=18.0,6.0 \mathrm{~Hz}, 2 \mathrm{H}), 7.78(\mathrm{~m}, 1 \mathrm{H}), 7.50(\mathrm{t}, J=7.5 \mathrm{~Hz}, 1 \mathrm{H}), 6.94-6.90(\mathrm{dd}, J=9.0,3.0 \mathrm{~Hz}, 2 \mathrm{H})$, $4.18(\mathrm{t}, J=6.0 \mathrm{~Hz}, 2 \mathrm{H}), 3.76(\mathrm{t}, J=7.5 \mathrm{~Hz}, 4 \mathrm{H}), 2.85(\mathrm{t}, J=4.5 \mathrm{~Hz}, 2 \mathrm{H}), 2.61(\mathrm{t}, J=4.5 \mathrm{~Hz}, 4 \mathrm{H})$; ${ }^{13} \mathrm{C}$ NMR $\left(75 \mathrm{MHz}, \mathrm{CDCl}_{3}\right) \delta=161.50,160.55,152.52,135.09,134.91,130.55,127.80,123.80$, $121.10,119.96,112.88,111.29,102.25,66.91,66.25,57.43,54.13$; HRMS (ESI) $m / z$ calcd for $\mathrm{C}_{19} \mathrm{H}_{20} \mathrm{NO}_{4}{ }^{+}[\mathrm{M}+\mathrm{H}]^{+}$: 326.1314; found: 326.1310. Chromatographic purity: 99.2\% (HPLC). 
3.1.3. General Procedure for the Synthesis of 3-Hydroxy-6H-benzo[c]chromen-6-one (II)

Using 2-bromo-5-methoxybenzoic acid $(60 \mathrm{mmol}, 13.79 \mathrm{~g})$ acid as the starting material, the synthesis method was similar to that of compound I, the desired yellow solid II was isolated (6.82 g, 47.0\%). M.p. 258.4-261.7 ${ }^{\circ} \mathrm{C} .{ }^{1} \mathrm{H}$ NMR $\left(300 \mathrm{MHz}, \mathrm{DMSO}-d_{6}\right) \delta=10.22$ $(\mathrm{s}, 1 \mathrm{H}), 8.21(\mathrm{~d}, J=9.0 \mathrm{~Hz}, 1 \mathrm{H}), 8.09(\mathrm{~d}, J=8.0 \mathrm{~Hz}, 1 \mathrm{H}), 7.60(\mathrm{~d}, J=3.0 \mathrm{~Hz}, 1 \mathrm{H}), 7.49(\mathrm{dd}$, $J=9.0,3.0 \mathrm{~Hz}, 1 \mathrm{H}), 6.83(\mathrm{dd}, J=9.0,3.0 \mathrm{~Hz}, 1 \mathrm{H}), 6.75(\mathrm{~d}, J=3.0 \mathrm{~Hz}, 1 \mathrm{H}), 3.89(\mathrm{~s}, 3 \mathrm{H}) ;{ }^{13} \mathrm{C}$ NMR $\left(75 \mathrm{MHz}\right.$, DMSO- $\left.d_{6}\right) \delta=160.97,159.41,158.94,151.62,128.97,124.57,124.36,123.99$, $120.48,113.55,111.27,109.96,103.30,56.01$; HRMS (ESI) $m / z$ calcd for $\mathrm{C}_{14} \mathrm{H}_{10} \mathrm{O}_{4}{ }^{+}[\mathrm{M}+\mathrm{H}]^{+}$: 242.0579; found: 242.0575. Chromatographic purity: 97.2\% (HPLC).

\subsubsection{General Procedures for Synthesis of Compounds $\mathbf{2 a}-\mathbf{w}$}

The anhydrous DMF ( $30 \mathrm{~mL}$ ) was added to a $250 \mathrm{~mL}$ round bottom flask, compound II (9.4 mmol, $2.28 \mathrm{~g})$, anhydrous $\mathrm{K}_{2} \mathrm{CO}_{3}(12.2 \mathrm{mmol}, 1.7 \mathrm{~g})$ and halides $(12.2 \mathrm{mmol})$ were added, and the temperature was controlled at $80 \sim 120^{\circ} \mathrm{C}$, the reaction was stirred for $24 \mathrm{~h}$. The reaction was monitored by TLC (PE:EA $=3: 1)$. When the reaction was over, the reaction solution was to the ice-water mixture to obtain brown crude solid. After suction filtration and drying, the brown crude solid was purified by column chromatography to obtain compounds $2 \mathbf{a}-\mathbf{w}$.

3,8-Dimethoxy-6H-benzo[c]chromen-6-one (2a): Using iodomethane as the starting material, the desired white solid 2a was isolated (1.23 g, 51\%). M.p. 146.2-148.8 ${ }^{\circ} \mathrm{C} .{ }^{1} \mathrm{H}$ NMR $\left(400 \mathrm{MHz}, \mathrm{DMSO}-d_{6}\right) \delta=8.22(\mathrm{~d}, J=9.0 \mathrm{~Hz}, 1 \mathrm{H}), 8.14(\mathrm{~d}, J=9.0 \mathrm{~Hz}, 1 \mathrm{H}), 7.58(\mathrm{~d}, J=3.0 \mathrm{~Hz}$, $1 \mathrm{H}), 7.47(\mathrm{dd}, J=9.0,3.0 \mathrm{~Hz}, 1 \mathrm{H}), 6.96(\mathrm{~s}, 1 \mathrm{H}), 6.94(\mathrm{t}, J=4.0 \mathrm{~Hz}, 1 \mathrm{H}), 3.89(\mathrm{~s}, 3 \mathrm{H}), 3.84$ $(\mathrm{s}, 3 \mathrm{H}) ;{ }^{13} \mathrm{C}$ NMR $\left(100 \mathrm{MHz}, \mathrm{DMSO}-d_{6}\right) \delta=160.85,160.83,159.23,151.55,128.55,12.50$, $124.34,124.31,120.79,112.69,111.30,111.21,101.79,56.15,56.04$; HRMS (ESI) $m / z$ calcd for $\mathrm{C}_{15} \mathrm{H}_{13} \mathrm{O}_{4}{ }^{+}[\mathrm{M}+\mathrm{H}]^{+}:$257.0736; found: 257.0731. Chromatographic purity: 99.2\% (HPLC).

3-Ethoxy-8-methoxy-6H-benzo[c]chromen-6-one (2b): Using bromoethane as the starting material, the desired white solid $\mathbf{2 b}$ was isolated(1.14 g, $45 \%)$. M.p. $141.1-143.8^{\circ} \mathrm{C} .{ }^{1} \mathrm{H}$ $\operatorname{NMR}\left(400 \mathrm{MHz}, \mathrm{DMSO}-d_{6}\right) \delta=8.26(\mathrm{~d}, J=8.0 \mathrm{~Hz}, 1 \mathrm{H}), 8.17(\mathrm{~d}, J=8.0 \mathrm{~Hz}, 1 \mathrm{H}), 7.62(\mathrm{~d}$, $J=4.0 \mathrm{~Hz}, 1 \mathrm{H}), 7.51(\mathrm{dd}, J=8.0,4.0 \mathrm{~Hz}, 1 \mathrm{H}), 6.98(\mathrm{~s}, 1 \mathrm{H}), 6.96(\mathrm{t}, J=4.0 \mathrm{~Hz}, 1 \mathrm{H}), 4.13$ $(\mathrm{q}, J=8.0 \mathrm{~Hz}, 2 \mathrm{H}), 3.90(\mathrm{~s}, 3 \mathrm{H}), 1.37(\mathrm{t}, J=8.0 \mathrm{~Hz}, 3 \mathrm{H}) ;{ }^{13} \mathrm{C}$ NMR $\left(75 \mathrm{MHz}\right.$, DMSO- $\left.d_{6}\right)$ $\delta=160.89,160.10,159.23,151.55,128.61,124.52,124.39,124.32,120.78,113.03,111.32,111.10$, 102.20, 64.19, 56.05, 14.95; HRMS (ESI) $m / z$ calcd for $\mathrm{C}_{16} \mathrm{H}_{15} \mathrm{O}_{4}{ }^{+}[\mathrm{M}+\mathrm{H}]^{+}:$271.0892; found: 271.0890. Chromatographic purity: $98.1 \%$ (HPLC).

8-Methoxy-3-propoxy-6H-benzo[c]chromen-6-one (2c): Using 1-bromopropane as the starting material, the desired white solid $2 \mathrm{c}$ was isolated $(1.39 \mathrm{~g}, 52 \%)$. M.p. $109.3-111.6{ }^{\circ} \mathrm{C} .{ }^{1} \mathrm{H}$ NMR $\left(400 \mathrm{MHz}, \mathrm{DMSO}-d_{6}\right) \delta=8.18(\mathrm{~d}, J=8.0 \mathrm{~Hz}, 1 \mathrm{H}), 8.09(\mathrm{~d}, J=8.0 \mathrm{~Hz}, 1 \mathrm{H}), 7.56(\mathrm{~d}$, $J=4.0 \mathrm{~Hz}, 1 \mathrm{H}), 7.45(\mathrm{dd}, J=8.0,4.0 \mathrm{~Hz}, 1 \mathrm{H}), 6.94-6.90(\mathrm{~m}, 2 \mathrm{H}), 3.99(\mathrm{t}, J=6.0 \mathrm{~Hz}, 2 \mathrm{H}), 3.88$ $(\mathrm{s}, 3 \mathrm{H}), 1.75(\mathrm{~m}, 2 \mathrm{H}), 1.00(\mathrm{t}, J=8.0 \mathrm{~Hz}, 3 \mathrm{H}) ;{ }^{13} \mathrm{C}$ NMR $\left(100 \mathrm{MHz}, \mathrm{DMSO}-d_{6}\right) \delta=160.86$, $160.23,159.20,151.52,128.58,124.46,124.33,124.27,120.75,113.00,111.29,111.08,102.20$, 69.95, 56.02, 22.37, 10.81; HRMS (ESI) $m / z$ calcd for $\mathrm{C}_{17} \mathrm{H}_{17} \mathrm{O}_{4}{ }^{+}[\mathrm{M}+\mathrm{H}]^{+}: 285.1049$; found: 285.1045. Chromatographic purity: $99.3 \%$ (HPLC).

3-(Sec-butoxy)-8-methoxy-6H-benzo[c]chromen-6-one (2d): Using 2-bromobutane as the starting material, the desired yellow solid $2 \mathbf{d}$ was isolated $(0.95 \mathrm{~g}, 34 \%)$. M.p. $64.5-66.7^{\circ} \mathrm{C}$. ${ }^{1} \mathrm{H}$ NMR $\left(400 \mathrm{MHz}\right.$, DMSO- $\left.d_{6}\right) \delta=8.21(\mathrm{~d}, J=8.0 \mathrm{~Hz}, 1 \mathrm{H}), 8.12(\mathrm{~d}, J=8.0 \mathrm{~Hz}, 1 \mathrm{H}), 7.59$ $(\mathrm{d}, J=4.0 \mathrm{~Hz}, 1 \mathrm{H}), 7.47(\mathrm{dd}, J=8.0,4.0 \mathrm{~Hz}, 1 \mathrm{H}), 6.95(\mathrm{~s}, 1 \mathrm{H}), 6.92(\mathrm{~d}, J=4.0 \mathrm{~Hz}, 1 \mathrm{H})$, $4.56-4.49(\mathrm{~m}, 1 \mathrm{H}), 3.89(\mathrm{~s}, 3 \mathrm{H}), 1.73-1.57(\mathrm{~m}, 2 \mathrm{H}), 1.27(\mathrm{~d}, J=6.0 \mathrm{~Hz}, 3 \mathrm{H}), 0.94(\mathrm{t}, J=8.0 \mathrm{~Hz}$, $3 \mathrm{H}) ;{ }^{13} \mathrm{C}$ NMR $\left(100 \mathrm{MHz}\right.$, DMSO- $\left.d_{6}\right) \delta=160.89,159.40,159.20,151.62,128.62,124.57,124.35$, 124.27, 120.77, 113.84, 111.32, 111.01, 103.23, 75.18, 56.03, 28.90, 19.37, 9.94; HRMS (ESI) $m / z$ calcd for $\mathrm{C}_{18} \mathrm{H}_{19} \mathrm{O}_{4}{ }^{+}[\mathrm{M}+\mathrm{H}]^{+}:$299.1205; found: 299.1201. Chromatographic purity: $98.7 \%$ (HPLC).

3-Butoxy-8-methoxy-6H-benzo[c]chromen-6-one (2e): Using 1-bromobutane as the starting material, the desired white solid $2 \mathrm{e}$ was isolated $\left(1.82 \mathrm{~g}\right.$, $65 \%$ ). M.p. $102.5-104.4{ }^{\circ} \mathrm{C} .{ }^{1} \mathrm{H}$ 
$\operatorname{NMR}\left(300 \mathrm{MHz}, \mathrm{DMSO}-d_{6}\right) \delta=8.26(\mathrm{~d}, J=9.0 \mathrm{~Hz}, 1 \mathrm{H}), 8.19-8.15(\mathrm{~m}, 1 \mathrm{H}), 7.62(\mathrm{~d}, J=3.0 \mathrm{~Hz}$, $1 \mathrm{H}), 7.51(\mathrm{dd}, J=9.0,3.0 \mathrm{~Hz}, 1 \mathrm{H}), 6.98(\mathrm{~s}, 1 \mathrm{H}), 6.96(\mathrm{t}, J=4.5 \mathrm{~Hz}, 1 \mathrm{H}), 4.07(\mathrm{t}, J=6.0 \mathrm{~Hz}$, $2 \mathrm{H}), 3.90(\mathrm{~s}, 3 \mathrm{H}), 1.78-1.68(\mathrm{~m}, 2 \mathrm{H}), 1.52-1.3840(\mathrm{~m}, 2 \mathrm{H}), 0.95(\mathrm{t}, J=7.5 \mathrm{~Hz}, 3 \mathrm{H}) ;{ }^{13} \mathrm{C} \mathrm{NMR}$ $\left(75 \mathrm{MHz}, \mathrm{DMSO}-d_{6}\right) \delta=160.84,160.25,159.20,151.52,128.58,124.43,124.29,124.24,120.75$, $112.99,111.31,111.08,102.21,68.21,56.02,31.06,19.17,14.14 ;$ HRMS (ESI) $m / z$ calcd for $\mathrm{C}_{18} \mathrm{H}_{19} \mathrm{O}_{4}{ }^{+}[\mathrm{M}+\mathrm{H}]^{+}:$299.1205; found: 299.1201. Chromatographic purity: 99.1\% (HPLC).

8-Methoxy-3-(pentyloxy)-6H-benzo[c]chromen-6-one (2f): Using 1-bromopentane as the starting material, the desired white solid $2 \mathrm{f}$ was isolated $(1.34 \mathrm{~g}, 46 \%)$. M.p. $73.1-75.5^{\circ} \mathrm{C}$. ${ }^{1} \mathrm{H}$ NMR $\left(300 \mathrm{MHz}, \mathrm{DMSO}-d_{6}\right) \delta=8.23(\mathrm{~d}, J=9.0 \mathrm{~Hz}, 1 \mathrm{H}), 8.15-8.12(\mathrm{~m}, 1 \mathrm{H}), 7.59(\mathrm{~d}$, $J=3.0 \mathrm{~Hz}, 1 \mathrm{H}), 7.49(\mathrm{dd}, J=8.0,3.0 \mathrm{~Hz}, 1 \mathrm{H}), 6.97-6.93(\mathrm{~m}, 2 \mathrm{H}), 4.03(\mathrm{t}, J=7.5 \mathrm{~Hz}, 2 \mathrm{H})$, $3.89(\mathrm{~s}, 3 \mathrm{H}), 1.78-1.69(\mathrm{~m}, 2 \mathrm{H}), 1.44-1.34(\mathrm{~m}, 4 \mathrm{H}), 0.93-0.88(\mathrm{~m}, 3 \mathrm{H}) ;{ }^{13} \mathrm{C}$ NMR $(75 \mathrm{MHz}$, DMSO- $\left.d_{6}\right) \delta=160.89,160.26,159.22,151.54,128.62,124.50,124.39,124.32,120.77,113.05$, 111.29, 111.09, 102.21, 68.49, 56.04, 28.70, 28.13, 22.37, 14.40; HRMS (ESI) $\mathrm{m} / \mathrm{z}$ calcd for $\mathrm{C}_{19} \mathrm{H}_{21} \mathrm{O}_{4}{ }^{+}[\mathrm{M}+\mathrm{H}]^{+}$: 313.1362; found: 313.1359. Chromatographic purity: 98.5\% (HPLC).

3-Isopropoxy-8-methoxy-6H-benzo[c]chromen-6-one (2g): Using 2-bromopropane as the starting material, the desired white solid $2 \mathrm{~g}$ was isolated $(0.97 \mathrm{~g}, 36 \%)$. M.p. 88.3-90.7 ${ }^{\circ} \mathrm{C}$. ${ }^{1} \mathrm{H}$ NMR $\left(300 \mathrm{MHz}, \mathrm{DMSO}-d_{6}\right) \delta=8.21(\mathrm{~d}, J=9.0 \mathrm{~Hz}, 1 \mathrm{H}), 8.14-8.11(\mathrm{~m}, 1 \mathrm{H}), 7.58(\mathrm{~d}$, $J=3.0 \mathrm{~Hz}, 1 \mathrm{H}), 7.48(\mathrm{dd}, J=9.0,3.0 \mathrm{~Hz}, 1 \mathrm{H}), 6.95-6.91(\mathrm{~m}, 2 \mathrm{H}), 4.75(\mathrm{~m}, 1 \mathrm{H}), 3.89(\mathrm{~s}, 3 \mathrm{H})$, $1.32(\mathrm{~d}, J=6.0 \mathrm{~Hz}, 6 \mathrm{H}) ;{ }^{13} \mathrm{C}$ NMR $\left(75 \mathrm{MHz}, \mathrm{DMSO}-d_{6}\right) \delta=160.89,159.19,159.05,151.60$, $128.60,124.55,124.34,124.26,120.76,113.81,111.30,110.98,103.20,70.33,56.03,22.14$; HRMS (ESI) $m / z$ calcd for $\mathrm{C}_{17} \mathrm{H}_{17} \mathrm{O}_{4}{ }^{+}[\mathrm{M}+\mathrm{H}]^{+}$: 285.1049; found: 285.1045. Chromatographic purity: $98.6 \%$ (HPLC).

3-(2-Hydroxyethoxy)-8-methoxy-6H-benzo[c]chromen-6-one (2h): Using 2-bromoethanol as the starting material, the desired yellow solid $2 \mathrm{~h}$ was isolated $(1.51 \mathrm{~g}, 56 \%)$. M.p. 166.8-168.0 ${ }^{\circ} \mathrm{C} .{ }^{1} \mathrm{H}$ NMR (300 MHz, DMSO- $\left.d_{6}\right) \delta=8.21(\mathrm{~d}, J=9.0 \mathrm{~Hz}, 1 \mathrm{H}), 8.15-8.11$ $(\mathrm{m}, 1 \mathrm{H}), 7.57(\mathrm{~d}, J=3.0 \mathrm{~Hz}, 1 \mathrm{H}), 7.47(\mathrm{dd}, J=9.0,3.0 \mathrm{~Hz}, 1 \mathrm{H}), 6.98-6.94(\mathrm{~m}, 2 \mathrm{H}), 4.98(\mathrm{t}$, $J=6.0 \mathrm{~Hz}, 1 \mathrm{H}), 4.08(\mathrm{dd}, J=6.0,3.0 \mathrm{~Hz}, 2 \mathrm{H}), 3.89(\mathrm{~s}, 3 \mathrm{H}), 3.77(\mathrm{q}, J=6.0 \mathrm{~Hz}, 2 \mathrm{H}) ;{ }^{13} \mathrm{C}$ NMR $\left(75 \mathrm{MHz}, \mathrm{DMSO}-d_{6}\right) \delta=160.86,160.25,159.19,151.50,128.55,124.48,124.33,124.26,120.76$, $113.05,111.26,111.14,102.28,70.56,59.89,56.02$; HRMS (ESI) $m / z$ calcd for $\mathrm{C}_{16} \mathrm{H}_{15} \mathrm{O}_{5}{ }^{+}[\mathrm{M}+$ $\mathrm{H}]^{+}$: 287.0841; found: 287.0837. Chromatographic purity: 98.8\% (HPLC).

8-methoxy-3-(2-(Methylthio)ethoxy)-6H-benzo[c]chromen-6-one (2i): Using (2-bromoethyl)(methyl)sulfane as the starting material, the desired white solid $2 \mathbf{i}$ was isolated $(1.18 \mathrm{~g}, 40 \%)$. M.p. $110.1-111.8{ }^{\circ} \mathrm{C} .{ }^{1} \mathrm{H}$ NMR $\left(300 \mathrm{MHz}, \mathrm{DMSO}-\mathrm{d}_{6}\right) \delta=8.27(\mathrm{~d}$, $J=9 \mathrm{~Hz}, 1 \mathrm{H}), 8.19(\mathrm{~d}, J=9.0 \mathrm{~Hz}, 1 \mathrm{H}), 7.62(\mathrm{~d}, J=3.0 \mathrm{~Hz}, 1 \mathrm{H}), 7.52(\mathrm{dd}, J=9.0,3.0 \mathrm{~Hz}$, $1 \mathrm{H}), 7.03-6.98(\mathrm{~m}, 2 \mathrm{H}), 4.26(\mathrm{t}, J=6.0 \mathrm{~Hz}, 2 \mathrm{H}), 3.90(\mathrm{~s}, 3 \mathrm{H}), 2.89(\mathrm{t}, J=7.5 \mathrm{~Hz}, 2 \mathrm{H}), 2.18(\mathrm{~s}$, $3 \mathrm{H}) ;{ }^{13} \mathrm{C} \mathrm{NMR}\left(75 \mathrm{MHz} \mathrm{CDCl}_{3}\right) \delta=165.60,164.53,164.05,156.28,133.29,129.33,129.13$, 125.61, 117.84, 116.16, 116.12, 107.21, 72.70, 60.82, 37.28, 20.45; HRMS (ESI) $m / z$ calcd for $\mathrm{C}_{17} \mathrm{H}_{17} \mathrm{O}_{4} \mathrm{~S}^{+}[\mathrm{M}+\mathrm{H}]^{+}$: 317.0769; found: 317.0765. Chromatographic purity: 97.8\% (HPLC).

Ethyl 2-((8-Methoxy-6-oxo-6H-benzo[c]chromen-3-yl)oxy)acetate (2j): Using ethyl 2-bromoacetate as the starting material, the desired white solid $2 \mathbf{j}$ was isolated $(1.58 \mathrm{~g}, 51 \%)$. M.p. 151.5-152.8 ${ }^{\circ} \mathrm{C}$. ${ }^{1} \mathrm{H}$ NMR $\left(300 \mathrm{MHz}, \mathrm{DMSO}-d_{6}\right) \delta=8.28(\mathrm{~d}, J=9.0 \mathrm{~Hz}, 1 \mathrm{H}), 8.21(\mathrm{t}, J=6.0 \mathrm{~Hz}$, $1 \mathrm{H}), 7.62(\mathrm{~d}, J=3.0 \mathrm{~Hz}, 1 \mathrm{H}), 7.52(\mathrm{dd}, J=9.0,3.0 \mathrm{~Hz}, 1 \mathrm{H}), 7.03-6.99(\mathrm{~m}, 2 \mathrm{H}), 4.92(\mathrm{~s}, 2 \mathrm{H})$, $4.20(\mathrm{q}, J=6.0 \mathrm{~Hz}, 2 \mathrm{H}), 3.90(\mathrm{~s}, 3 \mathrm{H}), 1.23(\mathrm{t}, J=7.5 \mathrm{~Hz}, 3 \mathrm{H}) ;{ }^{13} \mathrm{C} \mathrm{NMR}\left(75 \mathrm{MHz}, \mathrm{DMSO}-d_{6}\right) \delta$ $=168.85,160.80,159.42,159.11,151.39,128.39$, 124.63, 124.48, 124.40, 120.98, 113.01, 111.93, $111.42,102.75,65.41,61.25,56.09,14.52$; HRMS (ESI) $m / z$ calcd for $\left.\mathrm{C} 18 \mathrm{H}_{17 O 6}+\mathrm{M}+\mathrm{H}\right]^{+}$: 329.0947; found: 329.0943. Chromatographic purity: 97.4\% (HPLC).

3-(Cyclopentylmethoxy)-8-methoxy-6H-benzo[c]chromen-6-one (2k): Using (bromomethyl)cyclopentane as the starting material, the desired white solid $\mathbf{2 k}$ was isolated (0.90 g, 30\%). M.p. 146.1-148.2 ${ }^{\circ} \mathrm{C} .{ }^{1} \mathrm{H}$ NMR (300 MHz, DMSO- $\left.d_{6}\right) \delta=8.26(\mathrm{~d}, J=9.0 \mathrm{~Hz}$, $1 \mathrm{H}), 8.17(\mathrm{t}, J=4.5 \mathrm{~Hz}, 1 \mathrm{H}), 7.62(\mathrm{~d}, J=3.0 \mathrm{~Hz}, 1 \mathrm{H}), 7.51(\mathrm{dd}, J=9.0,3.0 \mathrm{~Hz}, 1 \mathrm{H}), 6.99-6.95$ $(\mathrm{m}, 2 \mathrm{H}), 3.94(\mathrm{~d}, J=6.0 \mathrm{~Hz}, 2 \mathrm{H}), 3.90(\mathrm{~s}, 3 \mathrm{H}), 2.38-2.28(\mathrm{~m}, 1 \mathrm{H}), 1.82-1.74(\mathrm{~m}, 2 \mathrm{H}), 1.65-1.51$ $(\mathrm{m}, 4 \mathrm{H}), 1.38-1.27(\mathrm{~m}, 2 \mathrm{H}) ;{ }^{13} \mathrm{C}$ NMR $\left(75 \mathrm{MHz}, \mathrm{DMSO}-d_{6}\right) \delta=160.92,160.44,159.28,151.59$, 
$128.66,124.55,124.44,124.39,120.83,113.15,111.39,111.15,102.35,72.61,56.09,38.88$, 29.44, 25.41; HRMS (ESI) $m / z$ calcd for $\mathrm{C}_{20} \mathrm{H}_{21} \mathrm{O}_{4}{ }^{+}[\mathrm{M}+\mathrm{H}]^{+}$: 325.1362; found: 325.1360 . Chromatographic purity: $98.1 \%$ (HPLC).

8-Methoxy-3-((tetrahydrofuran-2-yl)methoxy)-6H-benzo[c]chromen-6-one (21): Using 2(bromomethyl)tetrahydrofuran as the starting material, the desired white solid 21 was isolated (1.71 g, 56\%). M.p. $113.1-115.5^{\circ} \mathrm{C}$. ${ }^{1} \mathrm{H}$ NMR $\left(300 \mathrm{MHz}, \mathrm{DMSO}-\mathrm{d}_{6}\right) \delta=8.27(\mathrm{~d}$, $J=9.0 \mathrm{~Hz}, 1 \mathrm{H}), 8.18(\mathrm{dd}, J=9.0,3.0 \mathrm{~Hz}, 1 \mathrm{H}), 7.62(\mathrm{~d}, J=3.0 \mathrm{~Hz}, 1 \mathrm{H}), 7.51(\mathrm{dd}, J=9.0,3.0 \mathrm{~Hz}$, $1 \mathrm{H}), 7.03-6.94(\mathrm{~m}, 2 \mathrm{H}), 4.23-4.15(\mathrm{~m}, 1 \mathrm{H}), 4.11-3.98(\mathrm{~m}, 2 \mathrm{H}), 3.90(\mathrm{~s}, 3 \mathrm{H}), 3.84-3.77(\mathrm{~m}$, 1H), 3.73-3.66 (m, 1H), 2.08-1.99 (m, 1H), 1.94-1.77 (m, 2H), 1.72-1.65 (m, 1H); ${ }^{13} \mathrm{C}$ NMR $\left(75 \mathrm{MHz}, \mathrm{DMSO}-d_{6}\right) \delta=160.86,160.14,159.27,151.51,128.57,124.52,124.36,120.83,113.09$, 111.35, 111.29, 102.39, 76.81, 71.08, 67.97, 56.06, 28.06, 25.67; HRMS (ESI) $m / z$ calcd for $\mathrm{C}_{19} \mathrm{H}_{19} \mathrm{O}_{5}{ }^{+}\left[\mathrm{M}+\mathrm{H}^{+}\right.$: 327.1154; found: 327.1150. Chromatographic purity: 99.2\% (HPLC).

3-((1,3-Dioxolan-2-yl)methoxy)-8-methoxy-6H-benzo[c]chromen-6-one (2m): Using 2(bromomethyl)-1,3-dioxolane as the starting material, the desired white solid $\mathbf{2 m}$ was isolated (0.93 g, 30\%). M.p. $147.9-150.1{ }^{\circ} \mathrm{C} .{ }^{1} \mathrm{H}$ NMR $\left(300 \mathrm{MHz}, \mathrm{DMSO}-\mathrm{d}_{6}\right) \delta=8.28(\mathrm{~d}$, $J=9.0 \mathrm{~Hz}, 1 \mathrm{H}), 8.19(\mathrm{~d}, J=9.0 \mathrm{~Hz}, 1 \mathrm{H}), 7.62(\mathrm{~d}, J=3.0 \mathrm{~Hz}, 1 \mathrm{H}), 7.52(\mathrm{dd}, J=9.0,3.0 \mathrm{~Hz}$, $1 \mathrm{H}), 7.04-6.99(\mathrm{~m}, 2 \mathrm{H}), 5.24(\mathrm{t}, J=3.0 \mathrm{~Hz}, 1 \mathrm{H}), 4.12(\mathrm{~d}, J=6.0 \mathrm{~Hz}, 2 \mathrm{H}), 4.01-3.96(\mathrm{~m}, 2 \mathrm{H})$, $3.90(\mathrm{~s}, 3 \mathrm{H}), 3.89-3.85(\mathrm{~m}, 2 \mathrm{H}) ;{ }^{13} \mathrm{C}$ NMR $\left(75 \mathrm{MHz}, \mathrm{DMSO}-d_{6}\right) \delta=160.87,159.76,159.38$, $151.49,128.52,124.63,124.48,124.45,120.94,113.12,111.62,111.41,102.62,101.57,69.02$, 65.03, 56.10; HRMS (ESI) $m / z$ calcd for $\mathrm{C}_{18} \mathrm{H}_{17} \mathrm{O}_{6}{ }^{+}[\mathrm{M}+\mathrm{H}]^{+}$: 329.0947; found:329.0943. Chromatographic purity: $97.6 \%$ (HPLC).

3-(Cyclohexylmethoxy)-8-methoxy-6H-benzo[c]chromen-6-one (2n): Using (bromomethyl)cyclohexane as the starting material, the desired white solid $\mathbf{2 n}$ was isolated (1.85 g, 38\%). M.p. 139.8-140.1 ${ }^{\circ} \mathrm{C} .{ }^{1} \mathrm{H}$ NMR $\left(300 \mathrm{MHz}, \mathrm{DMSO}-d_{6}\right) \delta=8.25(\mathrm{~d}, J=9.0 \mathrm{~Hz}$, $1 \mathrm{H}), 8.18-8.14(\mathrm{~m}, 1 \mathrm{H}), 7.61(\mathrm{~d}, J=3.0 \mathrm{~Hz}, 1 \mathrm{H}), 7.50(\mathrm{dd}, J=9.0,3.0 \mathrm{~Hz}, 1 \mathrm{H}), 6.99-6.95$ $(\mathrm{m}, 2 \mathrm{H}), 3.90(\mathrm{~s}, 3 \mathrm{H}), 3.87(\mathrm{~d}, J=6.3 \mathrm{~Hz}, 2 \mathrm{H}), 1.84-1.65(\mathrm{~m}, 6 \mathrm{H}), 1.33-1.04(\mathrm{~m}, 5 \mathrm{H}) ;{ }^{13} \mathrm{C}$ NMR $\left(75 \mathrm{MHz}\right.$, DMSO- $\left.d_{6}\right) \delta=160.91,160.43,159.26,151.58,128.66,124.54,124.42,124.37$, $120.81,113.10,111.37,111.12,102.33,73.67,56.08,37.43,29.65,26.49,25.70 ;$ HRMS (ESI) $m / z$ calcd for $\mathrm{C}_{21} \mathrm{H}_{23} \mathrm{O}_{4}{ }^{+}[\mathrm{M}+\mathrm{H}]^{+}:$339.1518; found: 339.1514. Chromatographic purity: 97.5\% (HPLC).

3-(2-(1,3-Dioxolan-2-yl)ethoxy)-8-methoxy-6H-benzo[c]chromen-6-one (2o): Using 2-(2bromoethyl)-1,3-dioxolane as the starting material, the desired white solid 20 was isolated (1.22 g, 38\%). M.p. 151.6-153.2 ${ }^{\circ} \mathrm{C} .{ }^{1} \mathrm{H}$ NMR (300 MHz, DMSO- $\left.d_{6}\right) \delta=8.27(\mathrm{~d}, J=9.0 \mathrm{~Hz}$, $1 \mathrm{H}), 8.20-8.17(\mathrm{~m}, 1 \mathrm{H}), 7.62(\mathrm{~d}, J=3.0 \mathrm{~Hz}, 1 \mathrm{H}), 7.51(\mathrm{dd}, J=9.0,3.0 \mathrm{~Hz}, 1 \mathrm{H}), 7.00-6.96$ $(\mathrm{m}, 2 \mathrm{H}), 5.02(\mathrm{t}, J=4.5 \mathrm{~Hz}, 1 \mathrm{H}), 4.18(\mathrm{t}, J=6.0 \mathrm{~Hz}, 2 \mathrm{H}), 3.95-3.91(\mathrm{~m}, 2 \mathrm{H}), 3.90(\mathrm{~s}, 3 \mathrm{H})$, 3.83-3.79 (m, 2H), $2.07(\mathrm{~m}, 2 \mathrm{H}) ;{ }^{13} \mathrm{C} \mathrm{NMR}\left(75 \mathrm{MHz}, \mathrm{CDCl}_{3}\right) \delta=161.64,159.88,159.13$, 151.57, 128.66, 124.48, 123.11, 122.82, 120.96, 112.70, 111.33, 110.92, 102.20, 101.86, 65.02, 64.08, 55.76, 33.59, 29.73; HRMS (ESI) $m / z$ calcd for $\mathrm{C}_{19} \mathrm{H}_{19} \mathrm{O}_{6}{ }^{+}[\mathrm{M}+\mathrm{H}]^{+}:$343.1103; found: 343.1101. Chromatographic purity: 96.9\% (HPLC).

8-Methoxy-3-((tetrahydro-2H-pyran-4-yl)methoxy)-6H-benzo[c]chromen-6-one (2p): Using 4-(bromomethyl)tetrahydro-2H-pyran as the starting material, the desired yellow solid $2 \mathbf{p}$ was isolated (1.79 g, 36\%). M.p. $168.1-168.5{ }^{\circ} \mathrm{C} .{ }^{1} \mathrm{H} \mathrm{NMR}\left(400 \mathrm{MHz}, \mathrm{CDCl}_{3}\right) \delta=7.94(\mathrm{~d}$, $J=8.0 \mathrm{~Hz}, 1 \mathrm{H}), 7.87(\mathrm{~d}, J=8.0 \mathrm{~Hz}, 1 \mathrm{H}), 7.78(\mathrm{~d}, J=4.0 \mathrm{~Hz}, 1 \mathrm{H}), 7.39(\mathrm{dd}, J=8.0,4.0 \mathrm{~Hz}, 1 \mathrm{H})$, $6.91(\mathrm{dd}, J=8.0,4.0 \mathrm{~Hz}, 1 \mathrm{H}), 6.86(\mathrm{~d}, J=4.0 \mathrm{~Hz}, 1 \mathrm{H}), 4.06(\mathrm{dd}, J=12.0,4.0 \mathrm{~Hz}, 2 \mathrm{H}), 3.94(\mathrm{~s}$, $3 \mathrm{H}), 3.88(\mathrm{~d}, J=8.0 \mathrm{~Hz}, 2 \mathrm{H}), 3.51-3.45(\mathrm{~m}, 2 \mathrm{H}), 2.19-2.0(\mathrm{~m}, 1 \mathrm{H}), 1.82-1.78(\mathrm{~m}, 2 \mathrm{H}), 1.56-1.46$ $(\mathrm{m}, 2 \mathrm{H}) ;{ }^{13} \mathrm{C}$ NMR $\left(75 \mathrm{MHz}, \mathrm{DMSO}-d_{6}\right) \delta=160.91,160.29,159.31,151.59,128.64,124.60$, $124.45,124.41,120.86,113.14,111.41,111.25,102.42,72.99,67.06,56.10,34.79,29.62 ;$ HRMS (ESI) $m / z$ calcd for $\mathrm{C}_{20} \mathrm{H}_{21} \mathrm{O}_{5}{ }^{+}[\mathrm{M}+\mathrm{H}]^{+}:$341.1311; found: 341.1307. Chromatographic purity: $97.4 \%$ (HPLC).

3-(Benzyloxy)-8-methoxy-6H-benzo[c]chromen-6-one (2q): Using (bromomethyl)benzene as the starting material, the desired white solid $\mathbf{2 q}$ was isolated $(1.04 \mathrm{~g}, 33 \%)$. M.p. 141.7-142.5 ${ }^{\circ} \mathrm{C} .{ }^{1} \mathrm{H} \mathrm{NMR}\left(300 \mathrm{MHz}, \mathrm{DMSO}-d_{6}\right) \delta=8.27(\mathrm{~d}, J=9.0 \mathrm{~Hz}, 1 \mathrm{H}), 8.20(\mathrm{~d}, J=9.0 \mathrm{~Hz}$, 
$1 \mathrm{H}), 7.62(\mathrm{~d}, J=3.0 \mathrm{~Hz}, 1 \mathrm{H}), 7.51-7.48(\mathrm{~m}, 3 \mathrm{H}), 7.45-7.33(\mathrm{~m}, 3 \mathrm{H}), 7.10-7.04(\mathrm{~m}, 2 \mathrm{H}), 5.22(\mathrm{~s}$, 2H), $3.90(\mathrm{~s}, 3 \mathrm{H}) ;{ }^{13} \mathrm{C}$ NMR $\left(75 \mathrm{MHz}, \mathrm{DMSO}-d_{6}\right) \delta=162.53,159.77,158.99,151.43,136.98$, $128.96,128.33,124.30,121.58,120.60,113.25,111.25,102.70,70.15,55.98 ;$ HRMS (ESI) $\mathrm{m} / z$ calcd for $\mathrm{C}_{21} \mathrm{H}_{17} \mathrm{O}_{4}{ }^{+}[\mathrm{M}+\mathrm{H}]^{+}$: 333.1049; found: 333.1045. Chromatographic purity: 98.7\% (HPLC).

3-((4-[Hydroxymethyl]benzyl)oxy)-8-methoxy-6H-benzo[c]chromen-6-one (2r): Using (4(bromomethyl)phenyl)methanol as the starting material, the desired white solid $2 \mathbf{r}$ was isolated (1.26 g, 37\%). M.p. $192.4-194.6{ }^{\circ} \mathrm{C} .{ }^{1} \mathrm{H}$ NMR $\left(300 \mathrm{MHz}, \mathrm{DMSO}-d_{6}\right) \delta=8.27(\mathrm{~d}$, $J=9.0 \mathrm{~Hz}, 1 \mathrm{H}), 8.19(\mathrm{~d}, J=9.0 \mathrm{~Hz}, 1 \mathrm{H}), 7.62(\mathrm{~d}, J=3.0 \mathrm{~Hz}, 1 \mathrm{H}), 7.51(\mathrm{dd}, J=9.0,3.0 \mathrm{~Hz}, 1 \mathrm{H})$, $7.44(\mathrm{dd}, J=6.0,3.0 \mathrm{~Hz}, 2 \mathrm{H}), 7.35(\mathrm{~d}, J=8.0 \mathrm{~Hz}, 2 \mathrm{H}), 7.08-7.03(\mathrm{~m}, 2 \mathrm{H}), 5.20(\mathrm{t}, J=6.0 \mathrm{~Hz}$, $3 \mathrm{H}), 4.51(\mathrm{~d}, J=3.0 \mathrm{~Hz}, 2 \mathrm{H}), 3.90(\mathrm{~s}, 3 \mathrm{H}) ;{ }^{13} \mathrm{C}$ NMR $\left(75 \mathrm{MHz}, \mathrm{DMSO}-d_{6}\right) \delta=160.86,159.87$, $159.32,151.49,142.91,135.27,128.55,128.18,127.01,124.57,124.40,120.88,113.43,111.44$, $111.39,102.84,70.11,63.11,56.08$; HRMS (ESI) $m / z$ calcd for $\mathrm{C}_{22} \mathrm{H}_{19} \mathrm{O}_{5}{ }^{+}[\mathrm{M}+\mathrm{H}]^{+}: 363.1154$; found: 363.1150. Chromatographic purity: 98.6\% (HPLC).

3-((3,5-Dimethoxybenzyl)oxy)-8-methoxy-6H-benzo[c]chromen-6-one (2s): Using 1(bromomethyl)-3,5-dimethoxybenzene as the starting material, the desired white solid 2s was isolated (1.59 g, 43\%). M.p. $153.6-155.3{ }^{\circ} \mathrm{C} .{ }^{1} \mathrm{H} \mathrm{NMR}\left(300 \mathrm{MHz}, \mathrm{CDCl}_{3}\right) \delta=7.89$ $(\mathrm{d}, J=9.0 \mathrm{~Hz}, 1 \mathrm{H}), 7.84(\mathrm{~d}, J=9.0 \mathrm{~Hz}, 1 \mathrm{H}), 7.73(\mathrm{~d}, J=3.0 \mathrm{~Hz}, 1 \mathrm{H}), 7.35(\mathrm{dd}, J=9.0,3.0 \mathrm{~Hz}$, $1 \mathrm{H}), 6.96(\mathrm{dd}, J=9.0,3.0 \mathrm{~Hz}, 1 \mathrm{H}), 6.89(\mathrm{~d}, J=3.0 \mathrm{~Hz}, 1 \mathrm{H}), 6.59(\mathrm{~d}, J=3.0 \mathrm{~Hz}, 2 \mathrm{H}), 6.42$ $(\mathrm{t}, J=3.0 \mathrm{~Hz}, 1 \mathrm{H}), 5.05(\mathrm{~s}, 2 \mathrm{H}), 3.91(\mathrm{~s}, 3 \mathrm{H}), 3.80(\mathrm{~s}, 6 \mathrm{H}) ;{ }^{13} \mathrm{C}$ NMR $\left(75 \mathrm{MHz}, \mathrm{DMSO}-d_{6}\right)$ $\delta=161.04,160.88,160.82,159.76,159.33,151.48,139.36,128.54,124.62,124.44,120.90,113.41$, $111.51,111.35,106.65,105.99,102.85,99.96,70.00,56.08,55.67,55.49$; HRMS (ESI) $m / z$ calcd for $\mathrm{C}_{23} \mathrm{H}_{21} \mathrm{O}_{6}{ }^{+}[\mathrm{M}+\mathrm{H}]^{+}$: 393.1260; found: 393.1257. Chromatographic purity: $98.3 \%$ (HPLC).

3-((2-Fluorobenzyl)oxy)-8-methoxy-6H-benzo[c]chromen-6-one (2t):Using 1-(bromomethyl)-2fluorobenzene as the starting material, the desired white solid $\mathbf{2 t}$ was isolated $(2.47 \mathrm{~g}, 75 \%)$. M.p. 203.6-204.9 ${ }^{\circ} \mathrm{C} .{ }^{1} \mathrm{H}$ NMR $\left(300 \mathrm{MHz}, \mathrm{DMSO}-d_{6}\right) \delta=8.30(\mathrm{~d}, J=9.0 \mathrm{~Hz}, 1 \mathrm{H}), 8.23(\mathrm{~d}$, $J=9.0 \mathrm{~Hz}, 1 \mathrm{H}), 7.64-7.58(\mathrm{~m}, 2 \mathrm{H}), 7.52(\mathrm{dd}, J=9.0,3.0 \mathrm{~Hz}, 1 \mathrm{H}), 7.49-7.42(\mathrm{~m}, 1 \mathrm{H}), 7.33-7.24$ $(\mathrm{m}, 2 \mathrm{H}), 7.15(\mathrm{~d}, J=3.0 \mathrm{~Hz}, 1 \mathrm{H}), 7.07(\mathrm{dd}, J=9.0,3.0 \mathrm{~Hz}, 1 \mathrm{H}), 5.25(\mathrm{~s}, 2 \mathrm{H}), 3.91(\mathrm{~s}, 3 \mathrm{H})$; ${ }^{13} \mathrm{C}$ NMR $\left(75 \mathrm{MHz}, \mathrm{DMSO}-d_{6}\right) \delta=159.49,159.27,151.59,130.17,130.06,129.80,128.58$, $124.55,124.42,124.37,123.26,122.89,121.09,115.70,115.42,112.90,111.78,111.00,102.74$, 64.17, 55.79; HRMS (ESI) $m / z$ calcd for $\mathrm{C}_{21} \mathrm{H}_{16} \mathrm{FO}_{4}{ }^{+}[\mathrm{M}+\mathrm{H}]^{+}:$351.0954; found: 351.0950 . Chromatographic purity: $97.6 \%$ (HPLC).

3-((1,3-Dimethyl-1H-pyrazol-5-yl)methoxy)-8-methoxy-6H-benzo[c]chromen-6-one (2u): Using 5-(bromomethyl)-1,3-dimethyl-1H-pyrazole as the starting material, the desired white solid $2 \mathbf{u}$ was isolated (1.71 g, 52\%). M.p. 184.6-186.6 ${ }^{\circ} \mathrm{C} .{ }^{1} \mathrm{H}$ NMR (300 MHz, DMSO- $\left.d_{6}\right) \delta$ $=8.29(\mathrm{~d}, J=9.0 \mathrm{~Hz}, 1 \mathrm{H}), 8.21(\mathrm{~d}, J=9.0 \mathrm{~Hz}, 1 \mathrm{H}), 7.63(\mathrm{~d}, J=3.0 \mathrm{~Hz}, 1 \mathrm{H}), 7.52(\mathrm{dd}, J=9.0$, $3.0 \mathrm{~Hz}, 1 \mathrm{H}), 7.15(\mathrm{~d}, J=3.0 \mathrm{~Hz}, 1 \mathrm{H}), 7.07(\mathrm{dd}, J=9.0,3.0 \mathrm{~Hz}, 1 \mathrm{H}), 6.19(\mathrm{~s}, 1 \mathrm{H}), 5.23(\mathrm{~s}, 2 \mathrm{H})$, 3.90 (s, 3H), $3.76(\mathrm{~s}, 3 \mathrm{H}), 2.12(\mathrm{~s}, 3 \mathrm{H}) ;{ }^{13} \mathrm{C} \mathrm{NMR}\left(75 \mathrm{MHz}, \mathrm{CDCl}_{3}\right) \delta=165.59,164.15,164.09$, $156.20,150.86,142.74,133.24,129.37,129.23,129.16,125.71,118.13,116.53,116.17,111.87$, 107.73, 65.66, 60.85, 18.37; HRMS (ESI) $m / z$ calcd for $\mathrm{C}_{21} \mathrm{H}_{19} \mathrm{~N}_{2} \mathrm{O}_{4}{ }^{+}[\mathrm{M}+\mathrm{H}]^{+}: 351.1267$; found: 351.1263. Chromatographic purity: 98.7\% (HPLC).

8-Methoxy-3-(pyrimidin-2-yloxy)-6H-benzo[c]chromen-6-one (2v): Using 2-bromopyrimidine as the starting material, the desired white solid $2 \mathbf{v}$ was isolated $(1.29 \mathrm{~g}, 23 \%)$. M.p. 212.3-214.0 ${ }^{\circ} \mathrm{C}$. ${ }^{1} \mathrm{H}$ NMR (300 MHz, DMSO- $\left.d_{6}\right) \delta=8.69(\mathrm{~d}, J=6.0 \mathrm{~Hz}, 2 \mathrm{H}), 8.38$ (dd, $J=9.0,6.0 \mathrm{~Hz}, 2 \mathrm{H}), 7.68(\mathrm{~d}, J=3.0 \mathrm{~Hz}, 1 \mathrm{H}), 7.57(\mathrm{dd}, J=9.0,3.0 \mathrm{~Hz}, 1 \mathrm{H}), 7.38(\mathrm{~d}, J=3.0 \mathrm{~Hz}$, $1 \mathrm{H}), 7.33(\mathrm{t}, J=4.5 \mathrm{~Hz}, 1 \mathrm{H}), 7.27(\mathrm{dd}, J=9.0,3.0 \mathrm{~Hz}, 1 \mathrm{H}), 3.93(\mathrm{~s}, 3 \mathrm{H}) ;{ }^{13} \mathrm{C} \mathrm{NMR}(75 \mathrm{MHz}$, $\left.\mathrm{CDCl}_{3}\right) \delta=160.11,158.86,152.24,149.99,126.84,123.51,122.38,122.22,120.83,117.40,115.74$, 114.80, 110.18, 109.98, 54.79; HRMS (ESI) $m / z$ calcd for $\mathrm{C}_{18} \mathrm{H}_{13} \mathrm{~N}_{2} \mathrm{O}_{4}{ }^{+}[\mathrm{M}+\mathrm{H}]^{+}: 321.0797$; found: 321.0794. Chromatographic purity: 96.8\% (HPLC).

3-(2-(1H-pyrazol-1-yl)ethoxy)-8-methoxy-6H-benzo[c]chromen-6-one (2w): Using 1-(2bromoethyl)- $1 H$-pyrazole as the starting material, the desired white solid $2 \mathbf{w}$ was isolated 
(1.93 g, 61\%). M.p. 159.0-161.1 ${ }^{\circ} \mathrm{C} .{ }^{1} \mathrm{H}$ NMR $\left(300 \mathrm{MHz}, \mathrm{DMSO}-d_{6}\right) \delta=8.32(\mathrm{~d}, J=9.0 \mathrm{~Hz}$, $1 \mathrm{H}), 8.22(\mathrm{~d}, J=9.0 \mathrm{~Hz}, 1 \mathrm{H}), 7.87(\mathrm{~d}, J=3.0 \mathrm{~Hz}, 1 \mathrm{H}), 7.67(\mathrm{~d}, J=3.0 \mathrm{~Hz}, 1 \mathrm{H}), 7.58-7.53(\mathrm{~m}$, $2 \mathrm{H}), 7.05-6.98(\mathrm{~m}, 2 \mathrm{H}), 6.32(\mathrm{t}, J=3.0 \mathrm{~Hz}, 1 \mathrm{H}), 4.59(\mathrm{t}, J=6.0 \mathrm{~Hz}, 2 \mathrm{H}), 4.50(\mathrm{t}, J=4.5 \mathrm{~Hz}, 2 \mathrm{H})$, $3.95(\mathrm{~s}, 3 \mathrm{H}) ;{ }^{13} \mathrm{C}$ NMR $\left(75 \mathrm{MHz}, \mathrm{DMSO}-d_{6}\right) \delta=160.83,159.59,159.35,151.49,139.37,131.06$, 128.47, 124.61, 124.41, 120.90, 113.10, 111.60, 111.39, 105.70, 102.55, 67.55, 56.08, 50.95; HRMS (ESI) $m / z$ calcd for $\mathrm{C}_{19} \mathrm{H}_{17} \mathrm{~N}_{2} \mathrm{O}_{4}{ }^{+}[\mathrm{M}+\mathrm{H}]^{+}:$337.1110; found: 337.1106. Chromatographic purity: $98.9 \%$ (HPLC).

\subsection{Enzymatic Assays}

The in vitro inhibitory activity of compounds $1 \mathbf{a}-\mathbf{u}$ and $2 \mathbf{a}-\mathbf{w}$ against PDE2, which used Bio-cAMP as substrate, are listed in Table 1. The specific experimental method was reported below [32].

Preparation of $1 *$ Rection Buffer: we took $1 \mathrm{~mL} \mathrm{10*Rection} \mathrm{Buffer,} \mathrm{added} 9 \mathrm{~mL}$ ultrapure water to swirl and mix well, and put it on ice; preparation of PDE2 solution: $210 \mu \mathrm{L}$ of $1^{*}$ Rection Buffer were added into a centrifuge tube, then $30 \mu \mathrm{L}$ PDE2 were added, mixed well, equal to 8-times dilution, and placed on ice; preparation of compound solution with gradient concentration: DMSO was used as the solvent to prepare $10 \mathrm{mM}$ compound solution, and then diluted with $1^{*}$ Rection Buffer. The solution with final concentrations of $40 \mathrm{nM}, 20 \mathrm{nM}, 10 \mathrm{nM}, 5 \mathrm{nM}, 2.5 \mathrm{nM}, 1.25 \mathrm{nM}$, and $0.625 \mathrm{nM}$ was prepared, respectively, and the solution was vortex mixed.

We took $2 \mu \mathrm{L}$ of the diluted compound solution of each concentration into the microplate, added $4 \mu \mathrm{L}$ PDE2 solution, numbered them A1-A9, added $2 \mu \mathrm{L} 1 *$ Rection Buffer and $4 \mu \mathrm{L}$ PDE2 into A10, added $2 \mu \mathrm{L}$ compound solution and $4 \mu \mathrm{L} 1^{*}$ Rection Buffer to A11, added $6 \mu \mathrm{L} 1^{*}$ Rection Buffer to A13, and ensured the three groups are parallel to each other. Centrifugation was carried out at $1000 \mathrm{R}$ and $25^{\circ} \mathrm{C}$ for about $2 \mathrm{~min}$. The reaction time was $0.5 \mathrm{~h}$ in the microporous plate thermostatic oscillator. After the reaction, $4 \mu \mathrm{L}$ Bio-cAMP was added to A1-A13, and centrifugation was carried out at $1000 \mathrm{R}$ and $25^{\circ} \mathrm{C}$ for about $2 \mathrm{~min}$ and reacted in a microporous plate thermoelectric oscillator for $1 \mathrm{~h}$.

Anti-Camp Alohascreen Acceptor and Streptavidin Coated Donor Bead were purchased from Perkin Elmer Company according to response volume: $1^{*}$ Immunoassay Buffer $549.32 \mu \mathrm{L}$ and $3.70 \mu \mathrm{L}$ anti-cAMP AlohaScreen Acceptor were collected under dark conditions. We took $1.98 \mu \mathrm{L}$ Streptavidin coated Donor Bead, mixed well, added $15 \mu \mathrm{L}$ mixture to each well after $1 \mathrm{~h}$ reaction, and reacted it in the dark for $1 \mathrm{~h}$. After the reaction, we tested it with multilabel microplate detector. According to the detection results, the inhibition rate was calculated according to the dilution ratio of the experimental system and the formula, and the $\mathrm{IC}_{50}$ of compound was calculated by GraphPad Prism 5 .

\subsection{Cell Assays}

\subsubsection{Solution Preparation}

We added $943 \mu \mathrm{L}$ of DMSO solution to $8.2 \mathrm{mg}$ of dexamethasone acetate to obtain a $20 \mathrm{mM}$ stock solution, froze it at $-20^{\circ} \mathrm{C}$, and diluted it to $2 \mathrm{mM}$ with serum-containing medium before use. The test compound was dissolved in DMSO to obtain a $20 \mathrm{mM}$ stock solution and stored at $-20^{\circ} \mathrm{C}$. Diluted with serum-containing medium to a concentration of $2 \times 100,2 \times 50,2 \times 25,2 \times 12.5,2 \times 6.25,2 \times 3.125 \mu \mathrm{M}$ before use. The control sample Bay 60-7550 stock solution with a concentration of $1 \mathrm{mM}$ was diluted with serum-containing medium to a concentration of $2 \times 0.1,2 \times 1,2 \times 2$, and $2 \times 4 \mu \mathrm{M}$ before use.

\subsubsection{Cell Culture and Dexamethasone Intervention}

After resuscitation, HT-22 cells were cultured in DMEM medium (containing 10\% FBS) at $37{ }^{\circ} \mathrm{C}$ with $5 \% \mathrm{CO}_{2}$. After the cells grew to more than $80 \%$ cell fusion, we passaged and seeded the plate, and the density of each well should be 10,000 cells / $100 \mu \mathrm{L} /$ well and cultured for $24 \mathrm{~h}$. After the cells adhered to the wall, drug intervention was given. 


\subsubsection{Drug Intervention}

$10 \mu \mathrm{L}$ solution of $2 \mathrm{mM}$ dexamethasone acetate was cultured at $37{ }^{\circ} \mathrm{C}$ for $30 \mathrm{~min}$. $100 \mu \mathrm{L}$ drug solution of $2 \times 100,2 \times 50,2 \times 25,2 \times 12.5,2 \times 6.25$, and $2 \times 3.125 \mu \mathrm{M}$ were added to make the final concentration of dexamethasone acetate $100 \mu \mathrm{M}$, and the final concentrations of the drug were 100, 50, 25, 12.5, 6.25, 3.125 $\mu \mathrm{M}$. After preparation, it took another $24 \mathrm{~h}$ to continue the culture. There were 5 replicate wells for each sample, and the normal control group, dexamethasone acetate-affected group, and positive control group were set at the same time (final concentration $0.1,1,2$, and $4 \mu \mathrm{M}$ ).

\subsubsection{MTT Color Experimental and Data Processing}

After the incubation, $50 \mu \mathrm{L}$ of MTT was added to each well, and it needed another $4 \mathrm{~h}$ to incubate. Discarded the upper matrix and the $150 \mu \mathrm{L}$ DMSO was added. To dissolve the blue-violet precipitate completely, the shaker was used to shake for $10 \mathrm{~min}$. Finally, the wavelength A 490 was measured. The data were expressed as mean $\pm \mathrm{sd}(n=5)$, and one-way anova analysis of variance was used for data statistics; $p<0.05$ is defined as a significant difference.

\section{Conclusions}

In this paper, a series of new $6 \mathrm{H}$-benzo[c] chromen-6-one derivatives were designed and synthesized with PDE2 as the potential therapeutic target, and the PDE2 inhibitory activity was tested at the enzyme level. The results showed that part of compounds exhibited good PDE2 inhibitory activity, such as $1 \mathrm{f}, 1 \mathrm{~h}, 1 \mathrm{i}, 1 \mathrm{l}, 1 \mathrm{~s}, 2 \mathrm{e}$, and 2i. Among them, $1 \mathrm{f}$ has the highest PDE2 inhibitory activity with $\mathrm{IC}_{50}$ value of $3.67 \pm 0.47 \mu \mathrm{M}$. The protective effects of compound 1f against corticosterone-induced HT-22 neurotoxicity were further verified. Compound $1 \mathbf{f}$ can protect HT-22 cells from corticosterone-induced death and rescue corticosterone-induced toxicity in a dose-dependent manner, which is probably associated with PDE2 inhibition. In the future, we will design and synthesize more active PDE2-inhibitors based on an analysis of the structure-activity relationship between compound $1 \mathrm{f}$ and $4 \mathrm{HTX}$ for the potential treatment of AD. In addition, the in vivo test would be performed in mouse models of $\mathrm{AD}$ to obtain more convincing and potentially therapeutic molecules.

Author Contributions: Synthesis, materials preparation and biological studies, L.T., Y.T., Y.X.; Synthesis and characterization, L.T., Y.X.; Biological activity studies and Validation, Y.W., Z.Z.; Supervision, J.J., G.S.; Writing-original draft, L.T., X.F.; Writing-review and editing, L.T., X.H. All authors have read and agreed to the published version of the manuscript.

Funding: This research was funded by the National Natural Science Foundation of China, grant number 81803471.

Institutional Review Board Statement: Not applicable.

Informed Consent Statement: Not applicable.

Data Availability Statement: Not applicable.

Conflicts of Interest: The authors declare no conflict of interest.

\section{References}

1. Shakeri, A.; Zirak, M.R.; Sahebkar, A. Ellagic Acid: A logical Lead for Drug Development. Curr. Pharm. Des. 2018, 24, 106-122. [CrossRef]

2. Rojanathammanee, L.; Puig, K.L.; Combs, C.K. Pomegranate Polyphenols and Extract Inhibit Nuclear Factor of Activated T-Cell Activity and Microglial Activation in Vitro and in a Transgenic Mouse Model of Alzheimer Disease. J. Nutr. 2013, 143, 597-605. [CrossRef] [PubMed]

3. West, T.; Atzeva, M.; Holtzman, D.M. Pomegranate Polyphenols and Resveratrol Protect the Neonatal Brain Against HypoxicIschemic Injury. Dev. Neurosci. 2007, 29, 363-372.

4. Campos-Esparza, M.D.R.; Torres-Ramos, M.A. Neuroprotection by Natural Polyphenols: Molecular Mechanisms. Cent. Nerv. Syst. Agents Med. Chem. 2010, 10, 269-277. [CrossRef] [PubMed] 
5. Hartman, R.E.; Shah, A.; Fagan, A.M.; Schwetye, K.E.; Parsadanian, M.; Schulman, R.N.; Finn, M.B.; Holtzman, D.M. Pomegranate Juice Decreases Amyloid Load and Improves Behavior in a Mouse Model of Alzheimer's Disease. Neurobiol. Dis. 2006, 24, 506-515. [CrossRef] [PubMed]

6. Choi, S.J.; Lee, J.H.; Heo, H.J.; Cho, H.Y.; Kim, H.K.; Kim, M.O.; Sun, S.H.; Shin, D.H. Punica Granatum Protects against Oxidative Stress in PC12 Cells and Oxidative Stress-Induced Alzheimer's Symptoms in Mice. J. Med. Food 2011, 14, 695-701. [CrossRef]

7. Kujawska, M.; Jourdes, M.; Kurpik, M.; Szulc, M.; Szaefer, H.; Chmielarz, P.; Kreiner, G.; Kuźniak, V.K.; Mikołajczak, P.L.; Teissedre, P.L.; et al. Neuroprotective Effects of Pomegranate Juice against Parkinson's Disease and Presence of Ellagitannins-Derived Metabolite-Urolithin A-in the Brain. Int. J. Mol. Sci. 2020, 21, 202. [CrossRef]

8. Singh, R.; Chandrashekharappa, S.; Bodduluri, S.R.; Baby, B.V.; Hegde, B.; Kotla, N.G.; Hiwale, A.A.; Saiyed, T.; Patel, P.; Vijay-Kumar, M.; et al. Enhancement of the Gut Barrier Integrity by a Microbial Metabolite Through the Nrf2 Pathway. Nat. Commun. 2019, 10, 2369-2379.

9. Garazd, Y.L.; Garazd, M.M. Natural Dibenzo[b,d]pypan-6-ones: Structural Diversity and Biological Activity. Chem. Nat. Compd. 2016, 52, 1-18. [CrossRef]

10. Cozza, G.; Gianoncelli, A.; Bonvini, P.; Zorzi, E.; Pasquale, R.; Rosolen, A.; Pinna, L.A.; Meggio, F.; Zagotto, G.; Moro, S. Urolithin as a Converging Scaffold Linking Ellagic Acid and Coumarin Analogues Design of Potent Protein Kinase CK2 Inhibitors. Chem. Med. Chem. 2011, 6, 2273-2286. [CrossRef]

11. García-Villalba, R.; Selma, M.V.; Espín, J.C.; Tomas-Barberan, F.A. Identification of Novel Urolithin Metabolites in Human Feces and Urine after the Intake of a Pomegranate Extract. J. Agric. Food Chem. 2019, 67, 11099-11107. [CrossRef]

12. Gaya, P.; Peirotén, Á.; Medina, M.; Álvarez, I.; Landete, J.M. Bifidobacterium Pseudocatenulatum INIA P815: The First Bacterium Able to Produce Urolithins A and B from Ellagic Acid. J. Funct. Foods 2018, 45, 95-99. [CrossRef]

13. Espin, J.C.; Larrosa, M.; García-Conesa, M.T.; Tomás-Barberán, F. Biological Significance of Urolithins, the Gut Microbial Ellagic Acid Derived Metabolites: The Evidence So Far. Evid. Based Complementary Altern. 2013, 2013, 270418. [CrossRef]

14. Tulipani, S.; Urpi-Asrda, M.; Garcia-Villalba, R.; Rabassa, M.; Lopez-Uriarte, P.; Bullo, M.; Jauregui, O.; Tomas-Barberan, F.; Salas-Salvado, J.; Espin, J.C.; et al. Urolithins Are the Main Urinary Microbial-Derived Phenolic Metabolites Discriminating A Moderate Consumption of Nuts in Free-Living Subjects with Diagnosed Metabolic Syndrome. J. Agric. Food Chem. 2012, 60, 8930-8940. [CrossRef]

15. Gonzalez-Barrio, R.; Truchado, P.; Garcia-Villaba, R.; Hervas, G.; Frutos, P.; Espin, J.C.; Tomas-Barberan, F. Metabolism of Oak Leaf Ellagitannins snd Urolithin Production in Beef Cattle. J. Agric. Food Chem. 2012, 60, 3068-3077. [CrossRef] [PubMed]

16. Larrosa, M.; Gonzalez-Sarrias, A.; Yanez-Gasscon, M.J.; Selma, M.V.; Azorin-Ortuno, M.; Toti, S.; Tomas-Barberan, F.; Dolara, P.; Espin, J.C. Anti-Inflammatory Properties of a Pomegranate Extract and Its Metabolite Urolithin-A in a Colitis Rat Model and the Effect of Colon Inflammation on Phenolic Metabolism. J. Nutr. Biochem. 2010, 21, 717-725. [CrossRef] [PubMed]

17. Sharma, M.; Li, L.Y.; Celver, J.; Killian, C.; Kovoor, A.; Seearm, N.P. Effects of Fruit Ellagitannin Extracts, Ellagic Acid, and Their Colonic Metabolite, Urolithin A, on Wnt Signaling. J. Agric. Food Chem. 2010, 58, 3965-3969. [CrossRef]

18. Liu, W.X.; Ma, H.; Frost, L.; Yuan, T.; Dain, J.A.; Seeram, N.P. Pomegranate Phenolics Inhibit Formation of Advanced Glycation Endproducts by Scavenging Reactive Carbonyl Species. Food Funct. 2014, 5, 2996-3004. [CrossRef] [PubMed]

19. Velagapudi, R.; Lepiarz, I.; El-Bakoush, A.; Katola, F.O.; Bhatia, H.; Fiebich, B.L.; Olajide, O. Induction of Autophagy and Activation of SIRT-1 Deacetylation Mechanisms Mediate Neuroprotection by the Pomegranate Metabolite Urolithin A in BV2 Microglia and Differentiated 3D Human Neural Progenitor Cells. Mol. Nutr. Food Res. 2019, 63, 1801237. [CrossRef]

20. Lee, G.; Park, J.S.; Lee, E.J.; Ahn, J.H.; Kim, H.S. Anti-Inflammatory and Antioxidant Mechanisms of Urolithinb in Activated Microglia. Phytomedicine 2019, 55, 50-57. [CrossRef]

21. Lyketsos, C.G.; Lopez, O.; Jones, B.; Fitzpatrick, A.L.; Breitner, J.; DeKosky, S. Prevalence of Neuropsychiatric Symptoms in Dementia and Mild Cognitive Impairment: Results from the Cardiovascular Health Study. JAMA J. Am. Med. Assoc. 2002, 288, 1475-1483. [CrossRef]

22. Bender, A.T.; Beavo, J.A. Cyclic Nucleotide Phosphodiesterases: Molecular Regulation to Clinical Use. Pharmacol. Rev. 2006, 58, 488-520. [CrossRef]

23. Beavo, J.A.; Brunton, L.L. Cyclic Nucleotide Research-Stillexpanding After Half a Century. Nat. Rev. Mol. Cell Biol. 2002, 3, 710-718. [CrossRef]

24. Lugnier, C. Cyclic Nucleotide Phosphodiesterase (PDE) Superfamily: A New Target for the Development of Specific Therapeuticagents. Pharmacol. Therapeut. 2006, 109, 366-398. [CrossRef] [PubMed]

25. Jiang, M.Y.; Han, C.; Zhang, C.; Zhou, Q.; Zhang, B.; Le, M.L.; Huang, M.X.; Wu, Y.N.; Luo, H.B. Discovery of Effective Phosphodiesterase 2 Inhibitors with Antioxidant Activities for the Treatment of Alzheimer's Disease. Bioorg. Med. Chem. Lett. 2021, 41, 128016. [CrossRef]

26. Gomez, L.; Xu, R.; Sinko, W.; Selfridge, B.; Vernier, W.; Ly, K.; Truong, R.; Metz, M.; Marrone, T.; Sebring, K.; et al. Mathematical and Structural Characterization of Strong Nonadditive Structure-Activity Relationship Caused by Protein Conformational Changes. J. Med. Chem. 2018, 61, 7754-7766. [CrossRef] [PubMed]

27. Zhu, J.; Yang, Q.Q.; Dai, D.D.; Huang, Q. X-Ray Crystal Structure of Phosphodiesterase 2 in Complex with a Highly Selective, Nanomolar Inhibitor Reveals a Binding-Induced Pocket Important for Selectivity. J. Am. Chem. Soc. 2013, 135, 11708-11711. [CrossRef] 
28. Gulcan, H.O.; Unlu, S.; Esiringu, İ.; Ercetin, T.; Sahin, Y.; Oz, D.; Sahin, M.F. Design, Synthesis and Biological Evaluation of Novel 6H-Benzo[C]Chromen-6-One, and 7,8,9,10-Tetrahydro-Benzo[C]Chromen-6-One Derivatives as Potential Cholinesterase Inhibitors. Bioorg. Med. Chem. 2014, 22, 5141-5154. [CrossRef] [PubMed]

29. Huang, X.F.; Cao, Y.J.; Zhen, J.; Zhang, D.W.; Kong, R.; Jiang, W.T.; Xu, Y.; Song, G.Q.; Ke, H.M.; Liu, L. Design, Synthesis of Novel Purin-6-One Derivatives as Phosphodiesterase 2 (PDE2) Inhibitors: The Neuroprotective and Anxiolytic-Like Effects. Bioorg. Med. Chem. Lett. 2019, 29, 481-486. [CrossRef]

30. Zhu, M.J.; Shi, J.; Chen, Y.; Huang, G.B.; Zhu, X.W.; Zhang, S.; Huang, X.F.; Song, G.Q.; Zhang, H.T.; Ke, H.M.; et al. Phosphodiesterase 2 Inhibitor Hcyb1 Reverses Corticosterone-Induced Neurotoxicity and Depression-Like Behavior. Psychopharmacology 2020, 237, 3215-3224. [CrossRef] [PubMed]

31. Xu, Y.; Pan, J.C.; Chen, L.; Zhang, C.; Sun, J.; Li, J.X.; Nguyen, L.; Nair, N.; Zhang, H.T.; O’Donnell, J. Phosphodiesterase-2 Inhibitor Reverses Corticosterone-Induced Neurotoxicity and Related Behavioural Changes via Cgmp/PKG Dependent Pathway. Int. J. Neuropsychopharmacol. 2013, 16, 835-847. [CrossRef] [PubMed]

32. Xu, H.; Xu, X.S.; Gao, Y.; Cao, Y.J.; Huang, X.F.; Kong, R.; Song, G.Q. Establishment of a High-Throughput Screening Model for Drugs Targeting Phosphodiesterase 2. Chin. J. New Drugs 2020, 29, 56. 